\title{
LEISHMANIOSE E PLANTAS MEDICINAIS: UMA REVISÃO
}

\author{
Mardjori Andrade Hellmann ${ }^{1}$ \\ Eli Danieli Marchesan ${ }^{2}$ \\ Leonardo Garcia Velasquez ${ }^{3}$
}

HELlMANN, M. A.; MARCHESAN, E. D.; VELASQUEZ, L. G. Leishmaniose e plantas medicinais: uma revisão. Arq. Cienc. Saúde UNIPAR, Umuarama, v. 22, n. 3, p. 217-231, set./dez. 2018.

\begin{abstract}
RESUMO: A leishmaniose, segundo a Organização Mundial de Saúde, é uma das mais negligenciadas doenças tropicais re-emergentes, sendo reportada em várias partes do globo. Diante das dificuldades encontradas com as drogas disponíveis no mercado atualmente, como a elevada toxicidade e, em alguns casos, resistência por parte do parasito, inúmeras pesquisas tem sido realizadas com o objetivo de encontrar novas alternativas para o tratamento da leishmaniose. Nesse contexto, chama-se a atenção para o foco em compostos oriundos de plantas, as quais podem apresentar moléculas que tragam bons resultados no futuro. O objetivo de presente trabalho foi o de realizar uma revisão bibliográfica sobre produtos naturais utilizados em pesquisas com Leishmania como potenciais agentes utilizados como forma de tratamento contra o referido parasita. Foram analisados artigos científicos publicados nos últimos 5 anos nas bases eletrônicas de dados indexados na base de dados da LILACS, PubMed e ScienceDirect, utilizando os descritores em português "plantas medicinais", "leishmania" e seus correspondentes em Inglês. Selecionaram-se 61 artigos de estudos científicos, oriundos de 17 países, a maioria realizada no Brasil e Índia. Com base nos mecanismos de ação propostos pelos autores dos trabalhos realizados com amastigotos de Leishmania, grande parte está associada com estresse oxidativo na célula e com alterações no ambiente do macrófago, criando espécies reativas que funcionam como microbicidas. É possível que um composto ativo de uma planta tenha mais de um alvo na célula, sendo capaz de interferir de diferentes maneiras, dependendo do tipo celular e dos alvos disponíveis. As vantagens da utilização da fitoterapia incluem o baixo custo, baixa incidência de efeitos colaterais e sua efetividade. Além disso, é importante que sejam consideradas as espécies vegetais disponíveis no local, visando à diminuição nos custos do fitoterápico.
\end{abstract}

PALAVRA-CHAVE: Compostos Naturais. Leishmania. Plantas Medicinais. Tratamento.

\section{LEISHMANIASIS AND MEDICINAL PLANTS: A REVIEW}

ABSTRACT: According to the World Health Organization, Leishmaniasis is one of the most neglected re-emerging tropical diseases, being reported in several parts of the globe. In view of the difficulties encountered with drugs currently available on the market, such as high toxicity and, in some cases, resistance by the parasite, research has been carried out to find new alternatives for treating this disease. The objective of this study was to carry out a literature review on natural products used in Leishmania studies as potential treatment agents against that parasite. Scientific papers published in the past five years on the LILACS, PubMed and ScienceDirect electronic databases were analyzed using the following descriptors in English language and their correspondent in Portuguese: "medicinal plants" and "leishmania". A total of 61 articles from 17 countries were selected, mostly from Brazil and India. Based on the action mechanisms proposed by the authors of the studies performed with Leishmania amastigotes, a great part is associated with the oxidative stress in the cell and with changes in the macrophage environment, creating reactive species that act as microbicides. It is possible that an active compound from a given plant has more than one target in the cell, being able to interfere in different ways depending on the cell type and available targets. The advantages of using phytotherapy include low cost, low incidence of side effects, and high effectiveness. In addition, it is important to consider locally available plant species aimed at reducing costs.

KEYWORD: Leishmaniasis. Medicinal Plants. Natural compounds. Treatment.

\section{Introdução}

A leishmaniose, segundo a Organização Mundial de Saúde (OMS), é uma das mais negligenciadas doenças tropicais re-emergentes, sendo reportada em várias partes do globo, com uma prevalência de aproximadamente 12 milhões de casos, em 98 países e incidência de leishmaniose cutânea (LC) e visceral de 1,5 a 2 milhões e 500 mil novos casos por ano, respectivamente (LIMA et al., 2015; MALEKI et al., 2016). Cerca de 350 milhões de pessoas correm risco de contrair a infecção (HUBERT et al., 2013; MANS et al., 2016), que apresenta mais de 20 mil mortes em decorrência direta da doença anualmente (BAPELA; KAISER; MEYER, 2017). Clinicamente, observa-se um amplo espectro de manifestações, que vão desde úlceras cutâneas, lesões em mucosas e em órgãos viscerais, como por exemplo o baço, fígado e medula óssea (MALEKI et al., 2016; MANS et al., 2016).

É uma doença parasitária, causada por aproximadamente 20 tipos diferentes de protozoários do gênero Leishmania, transmitida pelas fêmeas de várias espécies de flebotomíneos, do gênero Lutzomyia, a vários mamíferos, incluindo o homem. Todas as espécies de Leishmania se desenvolvem como promastigotos, forma infecciosa, com flagelos que são expelidas por meio do mosquito para o hospedeiro

DOI: 10.25110 /arqsaude.v22i3.2018.6921

${ }^{1}$ Universidade Paranaense - UNIPAR. Mestre em Plantas Medicinais e Fitoterápicos na Atenção Básica pela Universidade Paranaense - Unidade Sede de Umuarama. Especialista em Farmacologia Clínica pela Universidade Paranaense - Unidade de Francisco Beltrão (2012). Graduada em Biomedicina pela Universidade Paranaense - Unidade de Francisco Beltrão (2007). Atualmente é docente na Universidade Paranaense- UNIPAR nas disciplinas de Farmacologia Geral, Fitoterapia e Fisiologia e Biomédica - Promotor de saúde execução na SESA-PR no Hemonúcleo Regional de Francisco Beltrão- PR.

${ }^{2}$ Universidade Paranaense - UNIPAR. Graduação em Ciências Biológicas pela Universidade Paranaense (2007). Especialização em Análise Ambiental pela pela Universidade Paranaense (2009). Mestrado pela Universidade Tecnológica Federal do Paraná (UTFPR) em Pato Branco na linha de Produção Vegetal, (2011). Doutorado pelo programa de Pós-graduação em Agronomia UTFPR (2012-2016). Estágio Sanduíche realizado na Mississippi State University, Estados Unidos, no departamento de Weed Science (2014-2015). Atualmente professora da Universidade Paranaense (UNIPAR).

${ }^{3}$ Universidade Paranaense. Brasil. Farmacêutico Bioquímico formado pela Universidade Estadual de Londrina. Mestre em Análises Clínicas pela Universidade Estadual de Maringá. Doutor em Ciências pela USP - São Paulo - na área da Relação Patógeno Hospedeiro. Docente Titular da Universidade Paranaense - Área de atuação Profissional: Imunologia Básica, Imunologia Clínica, Biologia Molecular, Plantas medicinais com atividade imunomoduladora. 
enquanto esse suga o sangue. A outra forma evolutiva são os amastigotos, não flagelados, que se localizam no interior dos macrófagos do hospedeiro (MANS et al., 2016). Animais domésticos podem servir como reservatórios, especialmente o cachorro, e a falta de tratamento e vacinas efetivas para esses animais torna difícil o controle da doença (VANDESMET et al., 2015).

O ciclo de vida do parasito consiste em promastigotos móveis, flagelados, extracelulares $(10-15 \mu \mathrm{m})$ que estão presentes no trato digestivo do flebotomídeo que ao realizar o repasto sanguíneo infectam o hospedeiro mamífero. Os promastigotos são fagocitados por macrófagos do hospedeiro e se transformam em amastigotos, forma não móvel, esférica, não flagelada $(2-3 \mu \mathrm{m})$, que sobrevivem e se multiplicam dentro destas células (SINGH et al., 2014) Essas formas são capazes de resistir à ação microbicida da liberação de hidrolases das lisozimas e, assim, sobrevivem, e multiplicam-se dentro dos macrófagos. Eventualmente, as células hospedeiras sofrem lise, liberando os parasitos que se espalham para novas células e tecidos de diferentes órgãos (especialmente o baço, fígado e medula óssea, dependendo da espécie do parasito), causando lesões e destruição tecidual. A continuidade do ciclo se dá, posteriormente, pela picada do flebotomídeo (não infectado), que ingerem do hospedeiro infectado (caninos, marsupiais e roedores), sangue, linfa e macrófagos infectados com amastigotos de Leishmania. Estes migram para o intestino, onde se transformam em promastigotos e avançam para o esôfago e glândulas salivares, os quais, em um novo repasto sanguíneo irão infectar um novo hospedeiro (SINGH et al., 2014).

As manifestações clínicas da doença podem ser cutâneas, mucocutâneas, difusas e viscerais, podem ser localizadas, como lesões únicas, múltiplas ou sistêmica, com acometimento visceral. Leishmaniose visceral, causada pela L. donovani é a forma mais fatal da doença (BAPELA; KAISER; MEYER, 2017). As manifestações clínicas começam a aparecer entre semanas e meses após a infecção dependendo da sub espécie de Leishmania e também características do sistema imunológico do hospedeiro (MANS et al., 2016).

O tratamento farmacológico de escolha utilizado contra leishmaniose é o mesmo desenvolvido a mais de um século (MAQUIAVELI et al., 2016) e é dependente de antimoniais pentavalentes, miltefosina, anfotericina $\mathrm{B}$ e paromomicina. $\mathrm{O}$ tratamento com estibogluconato sódico ainda é a primeira linha de tratamento, com doses recomendadas de $20 \mathrm{mg}$ por quilo de peso por 20-30 dias, esse esquema de tratamento apresenta uma taxa de mais de $95 \%$ de cura, entretanto, em algumas regiões da Índia mais de $60 \%$ dos pacientes apresentam resistência ao tratamento (SINGH et al., 2014). Além disso, chama-se a atenção para os altos custos e efeitos adversos significantes observados na terapia convencional (BAPELA; KAISER; MEYER, 2017). Durante décadas, tem se observado o surgimento de cepas resistentes ao tratamento, que combinado com a toxicidade das drogas disponíveis justifica a busca por novos agentes terapêuticos (SANDJO et al., 2016).

Novas drogas antileishmania capazes de reduzir a carga parasitária em áreas endêmicas são necessárias (BAPELA; KAISER; MEYER, 2017). Entretanto, apesar da pesquisa contínua de ativos contra as doenças negligenciadas a partir de fontes naturais, poucas são derivadas de plantas
(SANDJO et al., 2016). Essa lacuna tem aumentando o interesse nos estudo de produtos naturais utilizados tradicionalmente, visto que a medicina popular é uma fonte de substâncias potencialmente úteis para o desenvolvimento de novos quimioterápicos, com melhor atividade e menos efeitos colaterais (HUBERT et al., 2013).

Diante do exposto, o presente estudo realizou um revisão bibliográfica sobre produtos naturais utilizados em pesquisas com Leishmania como potenciais agentes utilizados como forma de tratamento contra o referido parasita.

\section{Metodologia}

O presente estudo trata-se de uma análise de dados secundários, por meio de uma revisão da literatura sobre a utilização de plantas medicinais no tratamento da leishmaniose. Para tanto, foram analisados artigos científicos publicados nos últimos 5 anos, as buscas foram realizadas nas bases eletrônicas de dados indexados na base de dados da Literatura Latino-Americana e do Caribe em Ciências da Saúde (LILACS), PubMed e ScienceDirect, utilizando os descritores previamente consultados no DECs (Descritores em Ciências da Saúde) em português "plantas medicinais", "leishmania" e seus correspondentes em Inglês. Foram incluídos no estudo os artigos que mencionavam a utilização de plantas no tratamento da leishmaniose, que apresentaram resultados positivos, os trabalhos que abordavam outras fontes de tratamento, que não a natural, redigidos em outras línguas que não português e inglês ou com resultados negativos foram excluídos da pesquisa. Os trabalhos que foram identificados em mais de uma das bases de dados pesquisadas tiveram a sua primeira identificação incluída na pesquisa e as demais não foram consideradas a fim de não se contabilizar de forma duplicada o mesmo trabalho.

A análise dos artigos foi realizada em três etapas. A primeira foi avaliar os textos quanto ao título, na segunda etapa, foi realizada a leitura dos resumos dos artigos separados na primeira fase, foram selecionados os que avaliavam a utilização de plantas medicinais no tratamento da leishmaniose. Na sequência foi feita a avaliação integral dos artigos escolhidos na fase da leitura dos resumos, a fim de identificar os que citavam a planta utilizada, constituintes, uso popular e mecanismo de ação provável. As informações encontradas nos artigos foram sistematizadas e descritas.

\section{Resultados}

A tabela 1 mostra os resultados encontrados em cada uma das bases de dados pesquisadas, utilizando os descritores "plantas medicinais" e "leishmania". Dessa forma, foram selecionados 61 artigos de estudos científicos, oriundos de 17 países, que abordam o tema para apresentação no presente trabalho, sendo 49 trabalhos provenientes da América, 3 da Europa, 29 da Ásia e 14 da África. Desses 10 tiveram como alvo parasitos relacionados a forma visceral e 51 relacionados a forma tegumentar. 
Tabela 1: Resultado das buscas nas bases PubMed, LILACS e SciELO utilizando os descritores "plantas medicinais" e "leishmania".

\begin{tabular}{lccc}
\hline \multicolumn{1}{c}{ Base de Dados } & Total de Artigos & Excluídos após leitura de títulos e resumos & Selecionados \\
\hline PubMed & 80 & 64 & 16 \\
LILACS & 7 & 2 & 5 \\
ScienceDirect & 519 & 479 & 40 \\
Total & $\mathbf{6 0 6}$ & $\mathbf{5 4 5}$ & $\mathbf{6 1}$ \\
Fonte: Dados da pesquisa, 2017. & & &
\end{tabular}

Fonte: Dados da pesquisa, 2017.

Com base nos resultados obtidos a partir da metodologia previamente descrita foram construídas as tabelas $2 \mathrm{e}$ 3 , sendo que a tabela 2 traz informações referentes a estudos realizados com extratos de plantas contra formas promastigotas e a tabela 3 contra forma amasitgotas do parasito. As tabelas foram construídas baseando-se nas seguintes informações: País,nome científico, parte da planta utilizada, extrato/fração, espécie do parasito, principais compostos encon- trados, possível mecanismo de ação/atividade leishmanicida.

Pode-se observar em ambas as tabelas que a maioria dos trabalhos foi realizada no Brasil e Índia, com ressalva para o Irã. De fato estes países, juntamente com o Afeganistão, Síria e Peru são responsáveis pela maioria dos casos de leishmaniose no mundo (MCCONVILLE; HANDMAN, 2007).

Tabela 2: Estudos com formas Promastigotas

\begin{tabular}{|c|c|c|c|c|c|c|c|}
\hline País & Nome científico & $\begin{array}{c}\text { Parte da } \\
\text { planta } \\
\text { utilizada }\end{array}$ & $\begin{array}{c}\text { Extrato/ Fração } \\
\text { (F) }\end{array}$ & $\begin{array}{c}\text { Espécie do } \\
\text { parasito }\end{array}$ & Principais compostos & $\begin{array}{l}\text { Mecanismo de } \\
\text { ação - atividade } \\
\text { leishmanicida. }\end{array}$ & Referência \\
\hline Tunísia & Ferula comunis & $\mathrm{F} / \mathrm{FL}$ & O.E. & $\begin{array}{l}\text { L. major } \\
\text { L. infantum }\end{array}$ & $\begin{array}{c}\alpha \text {-Pineno; } \beta \text {-Pineno; } \\
\text { Mirceno; Menta; } \\
\alpha \text {-Eudesmol; } \\
\beta \text {-cariofileno; } \\
\gamma \text {-Eudesmol. }\end{array}$ & $\begin{array}{l}\text { Alteração na } \\
\text { membrana } \\
\text { mitocondrial. }\end{array}$ & $\begin{array}{c}\text { (ESSID et al., } \\
\text { 2015) }\end{array}$ \\
\hline Tunísia & Teucrium polium & $\mathrm{F} / \mathrm{FL}$ & O.E. & $\begin{array}{c}\text { L. major } \\
\text { L. infantum }\end{array}$ & $\begin{array}{c}\alpha \text {-Pineno; Fenchol; } \\
\beta \text {-Pineno; Mirceno; } \\
\text { Cineol; } \gamma \text {-terpineno; } \\
\beta \text {-cariofileno; } \\
\text { carvacrol. }\end{array}$ & $\begin{array}{l}\text { Alteração na } \\
\text { membrana } \\
\text { mitocondrial. }\end{array}$ & $\begin{array}{c}\text { (ESSID et al., } \\
\text { 2015) }\end{array}$ \\
\hline Tunísia & $\begin{array}{c}\text { Pelargonium } \\
\text { graviolens }\end{array}$ & $\mathrm{F} / \mathrm{FL}$ & O.E. & $\begin{array}{l}\text { L. major } \\
\text { L. infantum }\end{array}$ & $\begin{array}{c}\alpha \text { - Pineno; } \gamma \text {-terpinene; } \\
\text { citronelal Isso- } \\
\text { mentona; linalol; } \\
\beta \text {-cariofilno; citronelal } \\
\text { cimeno; } \alpha \text {-cadinol; } \\
\gamma \text {-Eudesmol. }\end{array}$ & $\begin{array}{l}\text { Alteração na } \\
\text { membrana } \\
\text { mitocondrial. }\end{array}$ & $\begin{array}{c}\text { (ESSID et al., } \\
\text { 2015) }\end{array}$ \\
\hline Brasil & $\begin{array}{c}\text { Stachytarpheta } \\
\text { cayennensis }\end{array}$ & $\mathrm{F}$ & Butanólico & L. amazonenses & $\begin{array}{l}\text { Verbascoside; } \\
\text { isoverbascoside; } \\
\text { ipolamiide. }\end{array}$ & $\begin{array}{l}\text { Inibição da enzima } \\
\text { arginase gerando } \\
\text { estresse oxidativo. }\end{array}$ & $\begin{array}{l}\text { (MAQUIAVEI } \\
\text { et al., 2016) }\end{array}$ \\
\hline Índia & Solanum torvum & $\mathrm{F}$ & $\begin{array}{l}\text { Metanólico; } \\
\text { Cloridrato de } \\
\text { metileno }\end{array}$ & L. donovani & N.A. & $\begin{array}{c}\text { Inibição de } \\
\text { proteínas do } \\
\text { citoesqueleto e } \\
\text { proteínas integrais } \\
\text { alterando a } \\
\text { morfologia e } \\
\text { viabilidade do } \\
\text { parasito. }\end{array}$ & $\begin{array}{l}\text { (HUBERT et } \\
\text { al., 2013) }\end{array}$ \\
\hline Índia & Solanocia mannii & $\mathrm{F}$ & $\begin{array}{l}\text { Metanólico; } \\
\text { Cloridrato de } \\
\text { metileno }\end{array}$ & L. donovani & N.A. & $\begin{array}{c}\text { Inibição de } \\
\text { proteínas do } \\
\text { citoesqueleto e } \\
\text { proteínas integrais } \\
\text { alterando a } \\
\text { morfologia e } \\
\text { viabilidade do } \\
\text { parasito. }\end{array}$ & $\begin{array}{l}\text { (HUBERT et } \\
\text { al., 2013) }\end{array}$ \\
\hline Suriname & $\begin{array}{c}\text { Solanum } \\
\text { lycocarpum }\end{array}$ & $\mathrm{F}$ & Aquoso & L. donovani & $\begin{array}{l}\text { Solamargina; } \\
\text { solasonina. }\end{array}$ & N.A. & $\begin{array}{c}\text { (MANS et al., } \\
\text { 2016) }\end{array}$ \\
\hline Iran & Pimpinella anisum & S & Metanólico & L. major & N.A. & $\begin{array}{c}\text { Aumenta a } \\
\text { produção de N.O. }\end{array}$ & $\begin{array}{l}\text { (MALEKI et } \\
\text { al., 2016) }\end{array}$ \\
\hline Índia & $\begin{array}{l}\text { Anisomeles } \\
\text { malabarica }\end{array}$ & $\mathrm{F}$ & Metanólico & L. donovani & N.A. & N.A. & $\begin{array}{c}\text { (ZAHIR et al., } \\
\text { 2012) }\end{array}$ \\
\hline India & Ricinus communis & $\mathrm{F} / \mathrm{S}$ & Metanólico & L. donovani & N.A. & N.A. & $\begin{array}{c}\text { (ZAHIR et al., } \\
\text { 2012) }\end{array}$ \\
\hline
\end{tabular}




\begin{tabular}{|c|c|c|c|c|c|c|c|}
\hline Portugal & $\begin{array}{l}\text { Cymbopogon } \\
\text { citratus }\end{array}$ & $\mathrm{F}$ & O.E & $\begin{array}{l}\text { L. infantum; } \\
\text { L.tropica; } \\
\text { L. major }\end{array}$ & $\begin{array}{l}\text { Geraniol; neral; } \\
\text { mirceno. }\end{array}$ & $\begin{array}{c}\text { Alteração no } \\
\text { potencial da } \\
\text { membrana } \\
\text { mitocondrial e } \\
\text { destruição da } \\
\text { membrana nuclear. }\end{array}$ & $\begin{array}{l}\text { (MACHADO } \\
\text { et al., 2012) }\end{array}$ \\
\hline Bélgica & $\begin{array}{l}\text { Acanthospermum } \\
\text { hispidum }\end{array}$ & $\mathrm{F} / \mathrm{FL}$ & Aquoso & L. mexicana & $\begin{array}{l}\text { Sesquiterpeno } \\
\text { lactonas. }\end{array}$ & $\begin{array}{l}\text { Reação com } \\
\text { grupos de } \\
\text { importância } \\
\text { vital gerando } \\
\text { citotoxicidade. }\end{array}$ & $\begin{array}{l}\text { (GANFON et } \\
\text { al., 2012) }\end{array}$ \\
\hline Irã & Artemisia annua & $\mathrm{F}$ & N.A & L. major & $\begin{array}{l}\text { Terpeno; artemisinina; } \\
\text { artemeter. }\end{array}$ & $\begin{array}{l}\text { Fragmentação do } \\
\text { material genético. }\end{array}$ & $\begin{array}{c}\text { (BAHMANI et } \\
\text { al., 2015) }\end{array}$ \\
\hline Brasil & Piper aduncum L. & $\mathrm{F}$ & Etanólico & $\begin{array}{l}\text { L. brasiliensis; } \\
\text { L. amazonenses }\end{array}$ & $\begin{array}{c}\text { Diidrochalcona } \\
\text { prenilada - } \\
\text { adunchalcona }\end{array}$ & N.A. & $\begin{array}{l}\text { (DAL PICOLO } \\
\text { et al., 2014) }\end{array}$ \\
\hline Brasil & $\begin{array}{l}\text { Syzygium cumini } \\
\text { (L.) }\end{array}$ & $\mathrm{F}$ & O.E. & $\begin{array}{l}\text { L. amazonenses. } \\
\text { (amastigota e } \\
\text { promastigota). }\end{array}$ & $\alpha$-pineno; $\beta$ - ocimeno. & $\begin{array}{l}\text { Imunomodulação } \\
\text { em decorrência } \\
\text { do aumento da } \\
\text { produção de N.O. }\end{array}$ & $\begin{array}{l}\text { ( RODRIGUES } \\
\text { et al., 2015) }\end{array}$ \\
\hline Índia & Tinospora cordifolia & $\mathrm{F}$ & Aquoso & L. donovani & $\begin{array}{c}\text { Alcaloides; } \\
\text { diterpenoides; } \\
\text { lactonas; glicosideos; } \\
\text { esteroides; } \\
\text { sesquiterpenos. }\end{array}$ & $\begin{array}{c}\text { Utilizada em } \\
\text { associação com } \\
\text { Cisplatina, (droga } \\
\text { nova com alta } \\
\text { hepatotoxicidade) } \\
\text { como } \\
\text { hepatoprotetora. }\end{array}$ & $\begin{array}{c}\text { (SACHDEVA, } \\
\text { SEHGAL, \& } \\
\text { KAUR, 2014) }\end{array}$ \\
\hline Brasil & Annona muricata & $\mathrm{S}$ & Metanólico & $\begin{array}{l}\text { L. major; } \\
\text { L. Mexicana; } \\
\text { L. donovani. }\end{array}$ & $\begin{array}{l}\text { Acetogenina; } \\
\text { corossolona; } \\
\text { annonacinona. }\end{array}$ & $\begin{array}{l}\text { L. donovani e } \\
\text { L. major foram } \\
\text { mais suscetível à } \\
\text { annonacinona. }\end{array}$ & $\begin{array}{l}\text { ( VILA-NOVA } \\
\text { et al., 2013) }\end{array}$ \\
\hline Brasil & $\begin{array}{l}\text { Platymiscium } \\
\text { floribundum }\end{array}$ & $\mathrm{C}$ & $\begin{array}{l}\text { Hexânico; } \\
\text { Clorofórmico; } \\
\text { Etanólico }\end{array}$ & $\begin{array}{l}\text { L. major; } \\
\text { L. Mexicana; } \\
\text { L. donovani. }\end{array}$ & Escoparona; Cumarina & $\begin{array}{l}\text { L. mexicana } \\
\text { mais suscetível a } \\
\text { annonacinone e } \\
\text { scoparone. }\end{array}$ & $\begin{array}{l}\text { ( VILA-NOVA } \\
\text { et al., 2013) }\end{array}$ \\
\hline Nigéria & Jatropha multifida & $\mathrm{C}$ & Metanólico & L. donovani. & $\begin{array}{c}\text { Diterpenoides Latirana } \\
\text { Macrocíclico }\end{array}$ & Citotóxico & $\begin{array}{c}\text { (FALODUN et } \\
\text { al., 2014) }\end{array}$ \\
\hline Índia & Azadirachta indica & $\mathrm{F}$ & $\begin{array}{c}\text { Hexânico; } \\
\text { Acetato de } \\
\text { Etila; Alcoólico } \\
\text { Aquoso }\end{array}$ & L. donovani. & $\begin{array}{l}\text { Nimbolideo; solamina; } \\
\text { gedunina; vepinina; } \\
\text { meldenina; azadirona. }\end{array}$ & $\begin{array}{l}\text { Fragmentação do } \\
\text { material genético; } \\
\text { despolarização } \\
\text { da membrana } \\
\text { mitocondrial } \\
\text { induzindo } \\
\text { apoptose; aumento } \\
\text { produção de ROS. }\end{array}$ & $\begin{array}{c}\text { (DAYAKAR et } \\
\text { al., 2015) }\end{array}$ \\
\hline Brasil & Piper amalago & $\mathrm{F}$ & Clorofórmico & $\begin{array}{l}\text { L. amazonensis. } \\
\text { (amastigotae } \\
\text { promastigota). }\end{array}$ & $\begin{array}{l}\text { Ácido Propanoico; } \\
\text { ésteres; lignina; } \\
\text { terpenos; amidas. }\end{array}$ & $\begin{array}{c}\text { Aumento da } \\
\text { produção de N.O. }\end{array}$ & $\begin{array}{c}\text { (CARRARA et } \\
\text { al., 2013) }\end{array}$ \\
\hline Brasil & $\begin{array}{c}\text { Piper } \\
\text { malocophyllum }\end{array}$ & $\mathrm{F}$ & O.E & $\begin{array}{l}\text { L. infantum } \\
\text { (amastigota e } \\
\text { promastigota). }\end{array}$ & Gibbilimbol B & $\begin{array}{l}\text { Alteração na } \\
\text { permeabilidade } \\
\text { da membrana } \\
\text { plasmática do } \\
\text { parasito. }\end{array}$ & $\begin{array}{l}\text { (VARELA et } \\
\text { al., 2016) }\end{array}$ \\
\hline Irã & $\begin{array}{l}\text { Euphorbia } \\
\text { eryadenia }\end{array}$ & $\mathrm{F}$ & Metanólico & L. major & N.A. & N.A. & $\begin{array}{c}\text { (OSKUEE et } \\
\text { al., 2014) }\end{array}$ \\
\hline Brasil & Dipteryx alata Vog. & $\mathrm{F}$ & Hexânico & L. amazonensis. & $\begin{array}{l}\text { Tanino; flavonoides; } \\
\text { triterpenos; esteroides. }\end{array}$ & $\begin{array}{l}\text { Atravessa a } \\
\text { membrana dos } \\
\text { macrófagos } \\
\text { e interfere } \\
\text { diretamente } \\
\text { na viabilidade } \\
\text { parasitária. }\end{array}$ & $\begin{array}{l}\text { (RIBEIRO et } \\
\text { al., 2014) }\end{array}$ \\
\hline Brasil & $\begin{array}{c}\text { Jacaranda } \\
\text { cuspidifolia Mart. }\end{array}$ & $\mathrm{F}$ & Etanólico & L. amazonenses & $\begin{array}{c}\text { Tanino; flavonoides; } \\
\text { alcaloides; esteroides; } \\
\text { saponinas. }\end{array}$ & $\begin{array}{l}\text { Atravessa a } \\
\text { membrana dos } \\
\text { macrófagos } \\
\text { e interfere } \\
\text { diretamente } \\
\text { na viabilidade } \\
\text { parasitária. }\end{array}$ & $\begin{array}{l}\text { (RIBEIRO et } \\
\text { al., 2014) }\end{array}$ \\
\hline
\end{tabular}




\begin{tabular}{|c|c|c|c|c|c|c|c|}
\hline Irã & $\begin{array}{l}\text { Calendula } \\
\text { officinalis }\end{array}$ & FL & Metanólico & L. major & $\begin{array}{l}\text { Alcaloides; saponinas; } \\
\text { triterpenos; } \\
\text { flavonoids. }\end{array}$ & N.A. & $\begin{array}{l}\text { (NIKMEHR et } \\
\text { al., 2014) }\end{array}$ \\
\hline Irã & Datura stramonium & $\mathrm{S}$ & Metanólico & L. major & $\begin{array}{l}\text { Alcaloides; saponinas; } \\
\text { triterpenos; } \\
\text { flavonoids. }\end{array}$ & N.A. & $\begin{array}{l}\text { (NIKMEHR et } \\
\text { al., 2014) }\end{array}$ \\
\hline Irã & Salvia officinalis & $\mathrm{F}$ & Metanólico & L. major & $\begin{array}{l}\text { Alcaloides; saponinas; } \\
\text { triterpenos; } \\
\text { flavonoides. }\end{array}$ & N.A. & $\begin{array}{l}\text { (NIKMEHR et } \\
\text { al., 2014) }\end{array}$ \\
\hline Peru & $\begin{array}{l}\text { Pseudelephantopus } \\
\text { spiralis (Less.) }\end{array}$ & $\mathrm{F}$ & Aquoso & L. infantum & $\begin{array}{c}\text { Sesquiterpeno tipo } \\
\text { Hirsutinolide - } \\
\text { lactonas }\end{array}$ & N.A. & $\begin{array}{l}\text { (GIRARDI et } \\
\text { al., 2015) }\end{array}$ \\
\hline Brasil & Lippia gracilis & $\mathrm{F}$ & O.E & L. chagasi & $\begin{array}{l}\text { Timol; } \beta \text {-cariofileno; } \\
\rho \text {-cimeno; carvacrol. }\end{array}$ & $\begin{array}{c}\text { Alteração nas } \\
\text { propriedades } \\
\text { das membranas } \\
\text { plasmáticas } \\
\text { causando sua } \\
\text { ruptura. }\end{array}$ & $\begin{array}{l}\text { (de MELO et } \\
\text { al., 2013) }\end{array}$ \\
\hline Cuba & $\begin{array}{l}\text { Chenopodium } \\
\text { ambrosioides }\end{array}$ & $\mathrm{F}$ & O.E & $\begin{array}{l}\text { L. infantum; } \\
\text { L. amazonensis. }\end{array}$ & $\begin{array}{l}\text { Ascaridol; carvacrol; } \\
\text { cariofileno. }\end{array}$ & Não conhecido & $\begin{array}{l}\text { (MONZOTE et } \\
\text { al., 2014) }\end{array}$ \\
\hline Paquistão & Ocimum basilicum & $\mathrm{F}$ & Metanólico & L. tropica & $\begin{array}{l}\text { Ácido rosmarinico; } \\
\text { ácido caféico; ácido } \\
\text { vaníllico; ácido } \\
\text { litospérmico; ácido } \\
\text { benzo-hidroxílico }\end{array}$ & N.A. & $\begin{array}{l}\text { (KHAN et al., } \\
\text { 2015) }\end{array}$ \\
\hline Cuba & $\begin{array}{l}\text { Chenopodium } \\
\text { ambrosioides }\end{array}$ & $\mathrm{F}$ & O.E & L. amazonenses & $\begin{array}{c}\text { p-cimeno; ascaridol; } \\
\text { carvacrol; isoscaridol; } \\
\text { acetado de } \\
\text { neomentila; tiglato } \\
\text { de hexila; óxido de } \\
\text { cariofileno; apiol. }\end{array}$ & $\begin{array}{c}\text { Relacionado } \\
\text { com ações } \\
\text { antioxidantes, } \\
\text { anti-inflamatórias e } \\
\text { imunoestimulantes } \\
\text { dos compostos. }\end{array}$ & $\begin{array}{l}\text { ( MONZOTE } \\
\text { et al., 2014) }\end{array}$ \\
\hline Brasil & Senna spectabilis & $\mathrm{F}$ & Extrato cru & L. major & Cassina; espectalina. & $\begin{array}{l}\text { Capacidade de se } \\
\text { ligar ao ergosterol } \\
\text { que constitui a } \\
\text { membrana de } \\
\text { Leishmania. }\end{array}$ & $\begin{array}{l}\text { (MELO et al., } \\
\text { 2014) }\end{array}$ \\
\hline Egito & Euphorbia peplus L. & $\mathrm{F}$ & Metanólico & L. donovani & $\begin{array}{l}\text { Simiarenol; } \\
\text { 1-Hexacosanol; } \\
\text { b-sitosterol; } \\
\text { b-sitosterol-3-O- } \\
\text { glicosideo }\end{array}$ & $\begin{array}{c}\text { Inibe o } \\
\text { crescimento } \\
\text { afetando } \\
\text { marcadores } \\
\text { celulares, } \\
\text { incluindo a } \\
\text { membrana celular. }\end{array}$ & $\begin{array}{l}\text { (AMIN, } \\
\text { MOAWAD, } \\
\text { \& HASSAN, } \\
\text { 2016) }\end{array}$ \\
\hline Argentina & Lessonia vadosa & $\mathrm{F}$ & $\begin{array}{l}\text { Extração } \\
\text { por fluído } \\
\text { supercrítico }\end{array}$ & $\begin{array}{l}\text { L. amazonensis; } \\
\text { L. infantum. } \\
\text { (amastigota e } \\
\text { promastigota). }\end{array}$ & Fucosterol & $\begin{array}{l}\text { Imunomodulação, } \\
\text { modificando } \\
\text { a resposta } \\
\text { antiparasitária dos } \\
\text { macrófagos. }\end{array}$ & $\begin{array}{c}\text { (BECERRA et } \\
\text { al., 2015) }\end{array}$ \\
\hline Brasil & Casearia sylvestris & $\mathrm{F}$ & Metanólico & L. infantum. & Casearina A, B, G e J & $\begin{array}{l}\text { Alteração na } \\
\text { permeabilidade } \\
\text { da membrana } \\
\text { plasmática. }\end{array}$ & $\begin{array}{l}\text { (BOU et al., } \\
\text { 2014) }\end{array}$ \\
\hline Brasil & $\begin{array}{c}\text { Myracrodruon } \\
\text { urundeuva (Engl.) } \\
\text { Fr. All. }\end{array}$ & $\mathrm{F}$ & O.E & $\begin{array}{l}\text { L. amazonensis. } \\
\text { (amastigotae } \\
\text { promastigota). }\end{array}$ & $\begin{array}{l}\beta \text {-mirceno; } \alpha \text {-mirceno; } \\
\text { ccariofileno. }\end{array}$ & $\begin{array}{c}\text { Altera a } \\
\text { permeabilidade } \\
\text { celular e interfere } \\
\text { no potencial } \\
\text { de membrana } \\
\text { da mitocôndria } \\
\text { levando ao estresse } \\
\text { oxidativo. }\end{array}$ & $\begin{array}{l}\text { (CARVALHO } \\
\text { et al., 2017) }\end{array}$ \\
\hline
\end{tabular}




\begin{tabular}{|c|c|c|c|c|c|c|c|}
\hline Índia & Glycyrrhiza glabra & $\mathrm{F}$ & Metanólico & $\begin{array}{l}\text { L. donovani } \\
\text { (amastigota e } \\
\text { promastigota). }\end{array}$ & $\begin{array}{l}\text { Ácido glicirrízico; } \\
\text { licochalona A; ácido } \\
\text { glicirretínico }\end{array}$ & $\begin{array}{l}\text { Inibição da enzima } \\
\text { HMGR e depleção } \\
\text { dos níveis de } \\
\text { ergosterol. }\end{array}$ & $\begin{array}{l}\text { (DINESH et } \\
\text { al., 2017) }\end{array}$ \\
\hline Brasil & $\begin{array}{c}\text { Zingiber officinalis } \\
\text { Roscoe }\end{array}$ & $\mathrm{R}$ & Aquoso & L. amazonensis. & $\begin{array}{l}\text { Flavonoides; } \\
\text { saponinas. }\end{array}$ & $\begin{array}{c}\text { Aumento da } \\
\text { produção de N.O. }\end{array}$ & $\begin{array}{l}\text { (DUARTE et } \\
\text { al., 2016) } \\
\end{array}$ \\
\hline Índia & Vitex peduncularis & $\mathrm{F}$ & Metanólico & $\begin{array}{l}\text { L. donovani } \\
\text { (amastigota e } \\
\text { promastigota) }\end{array}$ & $\begin{array}{l}\text { flavonol aglicon - } \\
\text { vitecetina }\end{array}$ & $\begin{array}{c}\text { Aumento da } \\
\text { produção de N.O. }\end{array}$ & $\begin{array}{l}\text { (RUDRAPAUL } \\
\text { et al., 2014) }\end{array}$ \\
\hline Brasil & $\begin{array}{c}\text { Pterodon pubescens } \\
\text { benth. }\end{array}$ & FR & $\begin{array}{l}\text { Extração } \\
\text { por fluído } \\
\text { supercrítico }\end{array}$ & $\begin{array}{l}\text { L. amazonensis. } \\
\text { (amastigota e } \\
\text { promastigota) }\end{array}$ & geranilgeraniol & $\begin{array}{c}\text { Possível atividade } \\
\text { inibitória } \\
\text { contra enzimas } \\
\text { específicas nos } \\
\text { parasitos. } \\
\end{array}$ & $\begin{array}{l}\text { (SANTOS et } \\
\text { al., 2016) }\end{array}$ \\
\hline Brasil & $\begin{array}{c}\text { Azadirachta indica } \\
\text { (A Juss.) }\end{array}$ & $\mathrm{F} / \mathrm{FR}$ & Etanólico & $\begin{array}{l}\text { L. amazonenses } \\
\text { (amastigota e } \\
\text { promastigota) }\end{array}$ & $\begin{array}{l}\text { Terpenoides - } \\
\text { limonoides. }\end{array}$ & N.A. & $\begin{array}{l}\text { (CARNEIRO et } \\
\text { al., 2012) }\end{array}$ \\
\hline Índia & $\begin{array}{l}\text { Zingiber zerumbet } \\
\text { (L.) Smith }\end{array}$ & $\mathrm{R}$ & O.E & $\begin{array}{l}\text { L. donovani. } \\
\text { (amastigota e } \\
\text { promastigota) }\end{array}$ & $\begin{array}{c}\text { Zerumbona; } \\
\text { Cariofileno; camfeno; } \\
\text { eucaliptol; Canfora. }\end{array}$ & $\begin{array}{l}\text { Induz o estresse } \\
\text { oxidativo e } \\
\text { aumento no nível } \\
\text { de peroxidação } \\
\text { lipídica com } \\
\text { alteração do } \\
\text { potencial de } \\
\text { membrana } \\
\text { mitocondrial que } \\
\text { leva à apoptose. }\end{array}$ & $\begin{array}{l}\text { (MUKHERJEE } \\
\text { et al., 2016) }\end{array}$ \\
\hline Brasil & Eugenia uniflora & $\mathrm{F}$ & Etanólico & $\begin{array}{l}\text { L. braziliensis } \\
\text { (promastigota) }\end{array}$ & $\begin{array}{c}\text { flavonoides } \\
\text {-miricitrina, quercetina } \\
\text { e quercetina-3- } \\
\text { O-ramnosídeo; } \\
\text { esteroides, } \\
\text { monoterpenos, } \\
\text { triterpenos, taninos, } \\
\text { antraquinonas, fenóis, } \\
\text { cineol. }\end{array}$ & N.A. & $\begin{array}{l}\text { (SANTOS et } \\
\text { al., 2013) }\end{array}$ \\
\hline Brasil & $\begin{array}{l}\text { Dimorphandra } \\
\text { gardneriana }\end{array}$ & $\mathrm{S}$ & $\begin{array}{c}\text { Hexânico; } \\
\text { Acetato de Etila; } \\
\text { Metanólico; } \\
\text { Aquoso } \\
\end{array}$ & $\begin{array}{l}\text { L. infantum } \\
\text { chagasi } \\
\text { (amastigotae } \\
\text { promastigota) } \\
\end{array}$ & Rutina; quercetina & $\begin{array}{l}\text { inibição da enzima } \\
\text { AChE gerando } \\
\text { danos a membrana } \\
\text { celular. } \\
\end{array}$ & $\begin{array}{l}\text { (VILA-NOVA } \\
\text { et al., 2012) }\end{array}$ \\
\hline Brasil & $\begin{array}{l}\text { Platymiscium } \\
\text { loribundum }\end{array}$ & $\mathrm{C}$ & $\begin{array}{l}\text { Hexânico, } \\
\text { Clorofórmico; } \\
\text { Etanólico }\end{array}$ & $\begin{array}{l}\text { L. infantum } \\
\text { chagasi } \\
\text { (amastigota e } \\
\text { promastigota) }\end{array}$ & cumarina, escoparona, & $\begin{array}{l}\text { inibição da enzima } \\
\text { AChE gerando } \\
\text { danos a membrana } \\
\text { celular. }\end{array}$ & $\begin{array}{l}\text { (VILA-NOVA } \\
\text { et al., 2012) }\end{array}$ \\
\hline Nigéria & $\begin{array}{c}\text { Vernonia } \\
\text { amygdalina }\end{array}$ & $\mathrm{F}$ & Metanólico & $\begin{array}{c}\text { L. major: } \\
\text { (amastigota e } \\
\text { promastigota) }\end{array}$ & $\begin{array}{l}\text { flavonoides e } \\
\text { saponinas taninos, } \\
\text { esteróis }\end{array}$ & $\begin{array}{l}\text { Possível aumento } \\
\text { de citocinas pro- } \\
\text { inflamatórias } \\
\text { ou indução de } \\
\text { espécies reativas } \\
\text { de Nitrogênio } \\
\text { resultando em } \\
\text { estresse oxidativo. }\end{array}$ & $\begin{array}{c}\text { (ALAWA et al., } \\
\text { 2012) }\end{array}$ \\
\hline Tunísia & $\begin{array}{l}\text { Artemisia herba- } \\
\text { alba }\end{array}$ & $\mathrm{F}$ & O.E & L. infantum & $\begin{array}{l}\text { Canfora; } 1,8 \text {-cineol; } \\
\text { chrysanthenona; } \\
\alpha \text {-thujona; } \beta \text {-thujona. }\end{array}$ & $\begin{array}{c}\text { Indução de } \\
\text { apoptose pela } \\
\text { parada do ciclo } \\
\text { celular em sub-G0 } \\
\text { / G1. }\end{array}$ & $\begin{array}{l}\text { (ALOUI et al., } \\
\text { 2016) }\end{array}$ \\
\hline Tunísia & $\begin{array}{l}\text { Artemisia } \\
\text { campestris }\end{array}$ & $\mathrm{F}$ & O.E & L. infantum & $\begin{array}{c}\beta \text {-pineno; limoneno; } \\
\alpha \text {-pineno; g-terpineno; } \\
\beta \text {-mirceno. }\end{array}$ & $\begin{array}{c}\text { Indução de } \\
\text { apoptose pela } \\
\text { parada do ciclo } \\
\text { celular em sub-G0 } \\
\text { / G1. }\end{array}$ & $\begin{array}{l}\text { (ALOUI et al., } \\
\text { 2016) }\end{array}$ \\
\hline $\begin{array}{l}\text { Arábia } \\
\text { Saudita }\end{array}$ & $\begin{array}{c}\text { Achillea } \\
\text { biebersteinii Afan. }\end{array}$ & FL & Metanólico & L. amazonensis & N.A. & N.A. & $\begin{array}{l}\text { (AL-SOKARI } \\
\text { et al., 2015) }\end{array}$ \\
\hline Brasil & $\begin{array}{l}\text { Ferula galbaniflua } \\
\text { resin; }\end{array}$ & RE & O.E & L. amazonensis & $\begin{array}{l}\text { Ftalato de etila } \\
\text { 8-pimareno de metila } \\
\text {-18-oate; } \beta \text {-pineno. }\end{array}$ & N.A. & $\begin{array}{l}\text { (ANDRADE et } \\
\text { al., 2016) }\end{array}$ \\
\hline
\end{tabular}




\begin{tabular}{|c|c|c|c|c|c|c|c|}
\hline Brasil & Casearia sylvestris & $\mathrm{F}$ & Metanólico & L. amazonensis & $\begin{array}{c}\text { Diterpenos; alcaloides; } \\
\text { esterois; saponinas; } \\
\text { Taninos; flavonoides }\end{array}$ & N.A. & $\begin{array}{l}\text { (ANTINARELI } \\
\text { et al., 2015) }\end{array}$ \\
\hline Argentina & $\begin{array}{c}\text { Stevia aristata D. } \\
\text { Don ex Hook. \& } \\
\text { Arn. }\end{array}$ & $\mathrm{F}$ & Diclorometanoo & L. braziliensis & $\begin{array}{c}\text { flavonoides } \\
\text { eupatorina; } \\
\text { cirsimaritina; } \\
\text { 5-desmetilsinensetina }\end{array}$ & N.A. & $\begin{array}{l}\text { (BEER et al., } \\
\text { 2016) }\end{array}$ \\
\hline Irã & $\begin{array}{c}\text { Zataria multiflora } \\
\text { Boiss }\end{array}$ & $\mathrm{F}$ & O.E; Metanólico & $\begin{array}{c}\text { L. tropica } \\
\text { (amastigota e } \\
\text { promastigota) }\end{array}$ & Carvacrol; timol & $\begin{array}{c}\text { Possível ação } \\
\text { sobre a membrana } \\
\text { celular causando } \\
\text { dano e depleção do } \\
\text { seu conteúdo. }\end{array}$ & $\begin{array}{l}\text { (DEZAKI et } \\
\text { al., 2016) }\end{array}$ \\
\hline Brasil & Allamanda schottii & $\mathrm{F} / \mathrm{R}$ & Diclorometano & $\begin{array}{l}\text { L. brasiliensis } \\
\text { L. amazonenses }\end{array}$ & Plumieride & Não conhecido & $\begin{array}{l}\text { (FILHO et al., } \\
\text { 2013) }\end{array}$ \\
\hline Brasil & $\begin{array}{c}\text { Eugenia } \\
\text { umbelliflora Berg }\end{array}$ & FR & Hexânico & $\begin{array}{l}\text { L. brasiliensis } \\
\text { L. amazonenses }\end{array}$ & $\begin{array}{l}\text { Meroterpenoide; } \\
\text { Eugenol A, }\end{array}$ & Não conhecido & $\begin{array}{l}\text { (FILHO et al., } \\
\text { 2013) }\end{array}$ \\
\hline Brasil & $\begin{array}{c}\text { Rapanea } \\
\text { ferruginea, }\end{array}$ & $\mathrm{F}$ & Etanólico & $\begin{array}{l}\text { L. brasiliensis } \\
\text { L. amazonenses }\end{array}$ & Ácido mirsinóico B. & Não conhecido & $\begin{array}{l}\text { (FILHO et al., } \\
\text { 2013) }\end{array}$ \\
\hline Brasil & $\begin{array}{c}\text { Garcinia } \\
\text { achachairu }\end{array}$ & $\mathrm{F} / \mathrm{S}$ & Metanólico & $\begin{array}{l}\text { L. brasiliensis } \\
\text { L. amazonenses }\end{array}$ & guttiferona $\mathrm{A}$ & Não conhecido & $\begin{array}{l}\text { (FILHO et al., } \\
\text { 2013) }\end{array}$ \\
\hline Brasil & $\begin{array}{c}\text { Solanum } \\
\text { sisymbriifolium }\end{array}$ & $\mathrm{F}$ & Clorofórmic & $\begin{array}{l}\text { L. brasiliensis } \\
\text { L. amazonenses }\end{array}$ & Cilistol A; cilistadiol & Não conhecido & $\begin{array}{l}\text { (FILHO et al., } \\
\text { 2013) }\end{array}$ \\
\hline Irã & Caesalpinia gilliesii & FL & Etanólico & L. major & $\begin{array}{c}\text { Diterpenoides; } \\
\text { isovouacaperol; } \\
\text { sitosterol; } \\
\text { flavonoides; ácido } \\
\text { gálico; taninos; } \\
\text { ácido benzoico; } \\
\text { homoisoflavonoides }\end{array}$ & $\begin{array}{c}\text { Possível relação } \\
\text { com atividade } \\
\text { antiviral e } \\
\text { larvicida. }\end{array}$ & $\begin{array}{l}\text { (MANJILI et } \\
\text { al., 2012) }\end{array}$ \\
\hline Irã & $\begin{array}{c}\text { Juniperus excelsa } \\
\text { M.Bieb. }\end{array}$ & $\mathrm{F}$ & Etanólico & L. major & terpenos & $\begin{array}{l}\text { Inibição da } \\
\text { peroxidação } \\
\text { lipídica. }\end{array}$ & $\begin{array}{l}\text { (MOEIN et al., } \\
\text { 2017) }\end{array}$ \\
\hline Brasil & Eugenia uniflora L. & $\mathrm{F}$ & O.E & $\begin{array}{l}\text { L. amazonensis. } \\
\text { (amastigota e } \\
\text { promastigota) }\end{array}$ & $\begin{array}{l}\text { Curzereno; } \gamma \text {-elemeno; } \\
\text { trans- } \beta \text {-elemenono }\end{array}$ & $\begin{array}{c}\text { Afeta os } \\
\text { fosfolipídios } \\
\text { nas membranas } \\
\text { plasmáticas } \\
\text { levando à lise } \\
\text { e estimulam a } \\
\text { despolarização } \\
\text { das membranas } \\
\text { mitocondriais } \\
\text { levando à } \\
\text { apoptose. }\end{array}$ & $\begin{array}{l}\text { (RODRIGUES } \\
\text { et al., 2013) }\end{array}$ \\
\hline Itália & $\begin{array}{c}\text { Eremurus persicus } \\
\text { (Jaub \& Spach) } \\
\text { Boiss. }\end{array}$ & $\mathrm{R}$ & Etanólico & L. infantum & $\begin{array}{c}\text { aloesaponol III } \\
\text { 8-metill eter(-)-ASME }\end{array}$ & $\begin{array}{l}\text { Inibição da } \\
\text { proliferação e/ } \\
\text { ou lise dos } \\
\text { promastigotos. }\end{array}$ & $\begin{array}{l}\text { (ROSSI et al., } \\
\text { 2017) }\end{array}$ \\
\hline $\begin{array}{l}\text { Burkina } \\
\text { Faso }\end{array}$ & Lantana ukambensis & $\mathrm{F}$ & Metanólico & L. donovani. & $\begin{array}{l}\text { Polifenois; triterpenos, } \\
\text { saponinas; flavanonas; }\end{array}$ & N.A. & $\begin{array}{l}\text { (SAWADOGO } \\
\text { et al., 2012) }\end{array}$ \\
\hline Irã & $\begin{array}{l}\text { Scrophularia striata } \\
\text { Boiss (S. striata) }\end{array}$ & $\mathrm{F}$ & Etanólico & $\begin{array}{c}\text { L. major } \\
\text { (amastigota e } \\
\text { promastigota) }\end{array}$ & $\begin{array}{l}\text { Alcaloids; resina } \\
\text { glicosídica; iridoides; }\end{array}$ & $\begin{array}{l}\text { Interferem com } \\
\text { o metabolismo } \\
\text { de aminoácidos } \\
\text { aromáticos no } \\
\text { parasito. }\end{array}$ & $\begin{array}{c}\text { (ZAHIRI et al., } \\
\text { 2016) }\end{array}$ \\
\hline
\end{tabular}

N.A.: Não se aplica; F: Folhas; FL: Flor; R: Raiz; FR: Fruto; S: Semente; C: Cerne; CA: Casca; RE: Resina; O.E: Oleo Essencial; N.O.: Óxido nítrico; TGI: Trato Gastrointestinal. 
Tabela 3: Estudos realizados com formas amastigotas.

\begin{tabular}{|c|c|c|c|c|c|c|c|}
\hline País & Nome científico & $\begin{array}{c}\text { Parte da } \\
\text { planta } \\
\text { utilizada }\end{array}$ & $\begin{array}{c}\text { Extrato/ Fração } \\
\text { (F) }\end{array}$ & $\begin{array}{l}\text { Espécie do } \\
\text { parasito }\end{array}$ & $\begin{array}{l}\text { Principais } \\
\text { compostos }\end{array}$ & $\begin{array}{l}\text { Mecanismo de } \\
\text { ação- atividade } \\
\text { leishmanicida. }\end{array}$ & Referência \\
\hline Brasil & Dorstenia mannii & N.A. & N.A. & L. amazonenses & $\begin{array}{l}\text { 4-hidroxilonchocar- } \\
\text { pina; 6,8-diprenile- } \\
\text { riodictiol; loncho- } \\
\text { carpina }\end{array}$ & N.A. & $\begin{array}{c}\text { (SANDJO et al., } \\
\text { 2016) }\end{array}$ \\
\hline Brasil & $\begin{array}{l}\text { Zanthoxylum } \\
\text { buesgenii }\end{array}$ & N.A. & N.A. & L. amazonenses & buesgenina & N.A. & $\begin{array}{c}\text { (SANDJO et al., } \\
\text { 2016) }\end{array}$ \\
\hline $\begin{array}{l}\text { África do } \\
\text { Sul }\end{array}$ & Bridelia mollis & $\mathrm{R}$ & Metanólico & L. donovani & $\begin{array}{c}\text { Polifenois; } \\
\text { triterpenos; } \\
\text { glicosideis; lignans. }\end{array}$ & $\begin{array}{c}\text { São necessários } \\
\text { estudos para } \\
\text { determinar o modo } \\
\text { de ação. }\end{array}$ & $\begin{array}{c}\text { (BAPELA, } \\
\text { KAISER, \& } \\
\text { MEYER, } 2017\end{array}$ \\
\hline $\begin{array}{l}\text { África do } \\
\text { Sul }\end{array}$ & $\begin{array}{l}\text { Syzygium } \\
\text { cordatum }\end{array}$ & $\mathrm{F}$ & Metanólico & L. donovani & $\begin{array}{c}\text { Terpenoides; } \\
\text { fenilropanoides; } \\
\text { flavonoids; taninos } \\
\text { hidrolisados; lignan. }\end{array}$ & $\begin{array}{c}\text { São necessários } \\
\text { estudos para } \\
\text { determinar o modo } \\
\text { de ação. }\end{array}$ & $\begin{array}{c}\text { (BAPELA, } \\
\text { KAISER, \& } \\
\text { MEYER, 2017) }\end{array}$ \\
\hline $\begin{array}{l}\text { África do } \\
\text { Sul }\end{array}$ & Vangueria infausta & $\mathrm{R}$ & Metanólico & L. donovani & $\begin{array}{l}\text { Terpenoides; } \\
\text { glicosideos. }\end{array}$ & $\begin{array}{c}\text { São necessários } \\
\text { estudos para } \\
\text { determinar o modo } \\
\text { de ação. }\end{array}$ & $\begin{array}{c}\text { (BAPELA, } \\
\text { KAISER, \& } \\
\text { MEYER, 2017) }\end{array}$ \\
\hline $\begin{array}{l}\text { África do } \\
\quad \text { Sul }\end{array}$ & Xylopia parviflora & $\mathrm{R}$ & Metanólico & L. donovani & $\begin{array}{l}\text { Isoquinolina } \\
\text { alcaloides; } \\
\text { acetogeninas; } \\
\text { terpenos; óleos } \\
\text { essenciais. }\end{array}$ & $\begin{array}{c}\text { São necessários } \\
\text { estudos para } \\
\text { determinar o modo } \\
\text { de ação. }\end{array}$ & $\begin{array}{c}\text { (BAPELA, } \\
\text { KAISER, \& } \\
\text { MEYER, 2017) }\end{array}$ \\
\hline Brasil & $\begin{array}{l}\text { Syzygium cumini } \\
\text { (L.) }\end{array}$ & $\mathrm{F}$ & O.E. & $\begin{array}{l}\text { L. amazonenses. } \\
\text { (amastigota e } \\
\text { promastigota). }\end{array}$ & $\begin{array}{l}\alpha \text {-pineno; } \beta \text { - } \\
\text { ocimeno. }\end{array}$ & $\begin{array}{l}\text { Imunomodulação } \\
\text { em decorrência } \\
\text { do aumento da } \\
\text { produção de N.O. }\end{array}$ & $\begin{array}{c}\text { (RODRIGUES et } \\
\text { al., 2015) }\end{array}$ \\
\hline Brasil & Piper amalago & $\mathrm{F}$ & Clorofórmico & $\begin{array}{l}\text { L. amazonensis. } \\
\text { (amastigotae } \\
\text { promastigota). }\end{array}$ & $\begin{array}{l}\text { Ácido Propanóico; } \\
\text { esteres; } \\
\text { lignans;,terpenos; } \\
\text { amidas. }\end{array}$ & $\begin{array}{c}\text { Aumento da } \\
\text { produção de N.O. }\end{array}$ & $\begin{array}{c}\text { (CARRARA et } \\
\text { al., 2013) }\end{array}$ \\
\hline Brasil & $\begin{array}{c}\text { Piper } \\
\text { malocophyllum }\end{array}$ & $\mathrm{F}$ & O.E & $\begin{array}{l}\text { L. infantum } \\
\text { (amastigota e } \\
\text { promastigota). }\end{array}$ & Gibbilimbol B & $\begin{array}{l}\text { Alteração na } \\
\text { permeabilidade } \\
\text { da membrana } \\
\text { plasmática do } \\
\text { parasito. }\end{array}$ & $\begin{array}{l}\text { (VARELA et al., } \\
\text { 2016) }\end{array}$ \\
\hline Peru & $\begin{array}{c}\text { Renealmina } \\
\text { thyrsoidea }\end{array}$ & $\mathrm{F}$ & Acetato de Etila & L. amazonensis & Diarilheptanoides & $\begin{array}{l}\text { induced the mRNA } \\
\text { level of Dectin-1 }\end{array}$ & $\begin{array}{l}\text { (CABANILLAS } \\
\text { et al., 2014) }\end{array}$ \\
\hline Brasil & $\begin{array}{c}\text { Croton cajucara } \\
\text { Benth }\end{array}$ & $\mathrm{F} / \mathrm{CA}$ & Hexânico & $\begin{array}{l}\text { L. amazonenses } \\
\text { (amastigotae } \\
\text { promastigota). }\end{array}$ & Terpenos & $\begin{array}{l}\text { Ativação da enzima } \\
\text { trypanothione } \\
\text { redutase. }\end{array}$ & $\begin{array}{l}\text { (LIMA et al., } \\
\text { 2015) }\end{array}$ \\
\hline Argentina & Lessonia vadosa & $\mathrm{F}$ & $\begin{array}{c}\text { Extração } \\
\text { por fluído } \\
\text { supercrítico }\end{array}$ & $\begin{array}{l}\text { L. amazonensis; } \\
\text { L. infantum. } \\
\text { (amastigota e } \\
\text { promastigota). }\end{array}$ & Fucosterol & $\begin{array}{l}\text { Imunomodulação, } \\
\text { modificando } \\
\text { a resposta } \\
\text { antiparasitária dos } \\
\text { macrófagos. }\end{array}$ & $\begin{array}{l}\text { (BECERRA et } \\
\text { al., 2015) }\end{array}$ \\
\hline Brasil & $\begin{array}{c}\text { Myracrodruon } \\
\text { urundeuva (Engl.) } \\
\text { Fr. All. }\end{array}$ & $\mathrm{F}$ & O.E & $\begin{array}{l}\text { L. amazonensis. } \\
\text { (amastigota e } \\
\text { promastigota). }\end{array}$ & $\begin{array}{l}\beta \text {-mirceno; } \\
\alpha \text {-mirceno; } \\
\text { cariofileno. }\end{array}$ & $\begin{array}{c}\text { Altera a } \\
\text { permeabilidade } \\
\text { celular einterfere } \\
\text { no potencial } \\
\text { de membrana } \\
\text { da mitocôndria } \\
\text { levando ao estresse } \\
\text { oxidativo. }\end{array}$ & $\begin{array}{c}\text { (CARVALHO et } \\
\text { al., 2017) }\end{array}$ \\
\hline Índia & Glycyrrhiza glabra & F & Metanólico & $\begin{array}{l}\text { L. donovani } \\
\text { (amastigota e } \\
\text { promastigota). }\end{array}$ & $\begin{array}{l}\text { Ácido Glicirrizico; } \\
\text { licochalona A; ácido } \\
\text { glicirretínico. }\end{array}$ & $\begin{array}{l}\text { Inibição da enzima } \\
\text { HMGR e depleção } \\
\text { dos níveis de } \\
\text { ergosterol. }\end{array}$ & $\begin{array}{c}\text { (DINESH et al., } \\
\text { 2017) }\end{array}$ \\
\hline Índia & Vitex peduncularis & $\mathrm{F}$ & Metanólico & $\begin{array}{l}\text { L. donovani } \\
\text { (amastigota e } \\
\text { promastigota) }\end{array}$ & $\begin{array}{l}\text { Aglicona - } \\
\text { vitecetina }\end{array}$ & $\begin{array}{c}\text { Aumento da } \\
\text { produção de N.O. }\end{array}$ & $\begin{array}{l}\text { (RUDRAPAUL } \\
\text { et al., 2014) }\end{array}$ \\
\hline
\end{tabular}




\begin{tabular}{|c|c|c|c|c|c|c|c|}
\hline Brasil & $\begin{array}{c}\text { Pterodon } \\
\text { pubescens benth. }\end{array}$ & FR & $\begin{array}{c}\text { Extração } \\
\text { por fluído } \\
\text { supercrítico }\end{array}$ & $\begin{array}{l}\text { L. amazonensis. } \\
\text { (amastigota e } \\
\text { promastigota) }\end{array}$ & geranilgeraniol & $\begin{array}{l}\text { Possível atividade } \\
\text { inibitória contra } \\
\text { enzimas específicas } \\
\text { nos parasitos. }\end{array}$ & $\begin{array}{c}\text { (SANTOS et al., } \\
\text { 2016) }\end{array}$ \\
\hline Índia & $\begin{array}{l}\text { Withania } \\
\text { somnifera }\end{array}$ & $\mathrm{R}$ & Etanólico & L. donovani. & Lactonas esteroidais & $\begin{array}{l}\text { Aumenta a eficácia } \\
\text { de fármacos anti- } \\
\text { leishmania através } \\
\text { da geração de } \\
\text { imunidade mediada } \\
\text { por IFN- } \square \text { e IL-12. }\end{array}$ & $\begin{array}{l}\text { (TRIPATHI et al., } \\
\text { 2017) }\end{array}$ \\
\hline Brasil & $\begin{array}{l}\text { Pterodon } \\
\text { pudescens }\end{array}$ & $\mathrm{F}$ & Etanólico & L. amazonensis. & $\begin{array}{l}\text { Taninos catequinos, } \\
\text { flavonas, esteroids, } \\
\text { triterpenoides, } \\
\text { flavonoides; } \\
\text { xantinas }\end{array}$ & $\begin{array}{l}\text { Induz a resistência } \\
\text { de macrófagos a L. } \\
\text { amazonenses. }\end{array}$ & $\begin{array}{c}\text { (ARRAIS-SILVA } \\
\text { et al., 2014) }\end{array}$ \\
\hline Brasil & $\begin{array}{c}\text { Azadirachta indica } \\
\text { (A Juss. })\end{array}$ & $\mathrm{F} / \mathrm{FR}$ & Etanólico & $\begin{array}{l}\text { L. amazonenses } \\
\text { (amastigota e } \\
\text { promastigota) }\end{array}$ & $\begin{array}{l}\text { Terpenoides - } \\
\text { limonoides. }\end{array}$ & N.A. & $\begin{array}{l}\text { (CARNEIRO et } \\
\text { al., 2012) }\end{array}$ \\
\hline Índia & $\begin{array}{l}\text { Zingiber zerumbet } \\
\text { (L.) Smith }\end{array}$ & $\mathrm{R}$ & O.E & $\begin{array}{l}\text { L. donovani. } \\
\text { (amastigota e } \\
\text { promastigota) }\end{array}$ & $\begin{array}{c}\text { Zerumbona; } \\
\text { cariofileno; } \\
\text { canfeno; eucaliptol; } \\
\text { Canfora. }\end{array}$ & $\begin{array}{c}\text { Induz o estresse } \\
\text { oxidativo e } \\
\text { aumento no nível de } \\
\text { peroxidação lipídica } \\
\text { com alteração } \\
\text { do potencial } \\
\text { de membrana } \\
\text { mitocondrial que } \\
\text { leva à apoptose. }\end{array}$ & $\begin{array}{l}\text { (MUKHERJEE } \\
\text { et al., 2016) }\end{array}$ \\
\hline Brasil & $\begin{array}{l}\text { Dimorphandra } \\
\text { gardneriana }\end{array}$ & $\mathrm{S}$ & $\begin{array}{l}\text { Hexânico; } \\
\text { Acetato de Etila; } \\
\text { Metanólico; } \\
\text { Aquoso }\end{array}$ & $\begin{array}{l}\text { L. infantum } \\
\text { chagasi } \\
\text { (amastigota e } \\
\text { promastigota) }\end{array}$ & Rutina; quercetina & $\begin{array}{l}\text { inibição da enzima } \\
\text { AChE gerando } \\
\text { danos a membrana } \\
\text { celular. }\end{array}$ & $\begin{array}{l}\text { (VILA-NOVA et } \\
\text { al., 2012) }\end{array}$ \\
\hline Brasil & $\begin{array}{l}\text { Platymiscium } \\
\text { loribundum }\end{array}$ & $\mathrm{C}$ & $\begin{array}{l}\text { Hexânico, } \\
\text { Clorofórmico; } \\
\text { Etanólico }\end{array}$ & $\begin{array}{l}\text { L. infantum } \\
\text { chagasi } \\
\text { (amastigota e } \\
\text { promastigota) }\end{array}$ & $\begin{array}{l}\text { cumarina, } \\
\text { escoparona, }\end{array}$ & $\begin{array}{l}\text { inibição da enzima } \\
\text { AChE gerando } \\
\text { danos a membrana } \\
\text { celular. }\end{array}$ & $\begin{array}{l}\text { (VILA-NOVA et } \\
\text { al., 2012) }\end{array}$ \\
\hline Nigéria & $\begin{array}{c}\text { Vernonia } \\
\text { amygdalina }\end{array}$ & $\mathrm{F}$ & Metanólico & $\begin{array}{c}\text { L. major: } \\
\text { (amastigota e } \\
\text { promastigota) }\end{array}$ & $\begin{array}{c}\text { flavanoides e } \\
\text { saponinas; taninos, } \\
\text { sterois }\end{array}$ & $\begin{array}{l}\text { Possível aumento } \\
\text { de citocinas pro- } \\
\text { inflamatórias } \\
\text { ou indução de } \\
\text { espécies reativas } \\
\text { de Nitrogênio } \\
\text { resultando em } \\
\text { estresse oxidativo. }\end{array}$ & $\begin{array}{l}\text { (ALAWA et al., } \\
\text { 2012) }\end{array}$ \\
\hline $\begin{array}{l}\text { Arábia } \\
\text { Saudita }\end{array}$ & $\begin{array}{c}\text { Periploca aphylla } \\
\text { Decne. }\end{array}$ & $\mathrm{F} / \mathrm{G}$ & Metanólico & L. infantum & N.A. & N.A. & $\begin{array}{c}\text { (AL-MUSAYEIB } \\
\text { et al., 2012) }\end{array}$ \\
\hline Irã & $\begin{array}{c}\text { Zataria multiflora } \\
\text { Boiss }\end{array}$ & $\mathrm{F}$ & O.E; Metanólico & $\begin{array}{c}\text { L. tropica } \\
\text { (amastigota e } \\
\text { promastigota) }\end{array}$ & Carvacrol; timol & $\begin{array}{l}\text { Possível ação sobre } \\
\text { a membrana celular } \\
\text { causando dano e } \\
\text { depleção do seu } \\
\text { conteúdo. }\end{array}$ & $\begin{array}{c}\text { (DEZAKI et al., } \\
\text { 2016) }\end{array}$ \\
\hline $\begin{array}{l}\text { Iêmem/ } \\
\text { Arábia } \\
\text { Saudita }\end{array}$ & $\begin{array}{c}\text { Verbascum bottae } \\
\text { (Deflers) Huber- } \\
\text { Mor. }\end{array}$ & $\mathrm{F}$ & Metanólico & L. infantum & N.A. & N.A. & $\begin{array}{l}\text { (MOTHANA et } \\
\text { al., 2013) }\end{array}$ \\
\hline Brasil & $\begin{array}{c}\text { Eugenia uniflora } \\
\text { L. }\end{array}$ & $\mathrm{F}$ & O.E & $\begin{array}{l}\text { L. amazonensis. } \\
\text { (amastigota e } \\
\text { promastigota) }\end{array}$ & $\begin{array}{c}\text { Curzereno; } \\
\text { elemeno; elemenone }\end{array}$ & $\begin{array}{c}\text { Afeta os } \\
\text { fosfolipídios } \\
\text { nas membranas } \\
\text { plasmáticas levando } \\
\text { à lise e estimulam } \\
\text { a despolarização } \\
\text { das membranas } \\
\text { mitocondriais } \\
\text { levando à apoptose. }\end{array}$ & $\begin{array}{l}\text { ( RODRIGUES } \\
\text { et al., 2013) }\end{array}$ \\
\hline Irã & $\begin{array}{c}\text { Scrophularia } \\
\text { striata Boiss ( } S . \\
\text { striata) }\end{array}$ & $\mathrm{F}$ & Etanólico & $\begin{array}{c}\text { L. major } \\
\text { (amastigota e } \\
\text { promastigota) }\end{array}$ & $\begin{array}{l}\text { Alcaloides; } \\
\text { glicosideos } \\
\text { resinados; iridoide }\end{array}$ & $\begin{array}{l}\text { Interferem com } \\
\text { o metabolismo } \\
\text { de aminoácidos } \\
\text { aromáticos no } \\
\text { parasito. }\end{array}$ & $\begin{array}{l}\text { (ZAHIRI et al., } \\
\text { 2016) }\end{array}$ \\
\hline
\end{tabular}

N.A.: Não se aplica; F: Folhas; FL: Flor; R: Raiz; FR: Fruto; S: Semente; C: Cerne; CA: Casca; RE: Resina; O.E: Óleo Essencial; N.O.: Oxido nítrico; TGI: Trato Gastrointestinal. 


\section{Discussão}

A leishmaniose é uma zoonose causada por parasitos do gênero Leishmania que infectam diversas células do organismo humano e desencadeiam uma série de alterações clínicas (KAYE; SCOTT, 2011), que vão desde alterações cutâneas até o comprometimento de órgão vitais, com o baço, fígado e medula óssea (MALEKI et al., 2016; MANS et al., 2016).

Diante das dificuldades encontradas com as drogas disponíveis no mercado, as quais tem apresentado elevada toxicidade (BAPELA; KAISER; MEYER, 2017) e, em alguns casos, resistência por parte do parasito (SANDJO et al., 2016), inúmeras pesquisas têm sido realizadas com o objetivo de encontrar novas alternativas para o tratamento da leishmaniose. Nesse contexto, chama-se a atenção para o foco em compostos oriundos de plantas, as quais podem apresentar moléculas que tragam bons resultados no futuro. É importante notar que por serem componentes de plantas é necessário que as substâncias sejam extraídas por meio de diferentes meios de extração. Assim, em alguns casos, o método de extração pode interferir diretamente na atividade farmacológica do extrato obtido (SANTOS et al., 2016).

Em alguns dos trabalhos avaliados, foram utilizados óleos essenciais provenientes das plantas (ALOUI et al., 2016; ANDRADE et al., 2016; CARVALHO et al., 2017; de MELO et al., 2013; DEZAKI et al., 2016; ESSID et al., 2015; MACHADO et al., 2012; MONZOTE, PASTOR, SCULL; GILLE, 2014; MONZOTE et al., 2014; MUKHERJEE et al., 2016; RODRIGUES et al., 2015; RODRIGUES et al., 2013; VARELA et al., 2016). Os componentes dos óleos essenciais possuem caráter lipofílico e dessa maneira, conseguem atravessar a membrana plasmática, interferindo na composição desta. Assim, a permeabilidade da membrana será alterada pela entrada do óleo essencial e a célula do parasito poderá sofrer lise (RODRIGUES et al., 2015).

Na tabela 2 estão descritos os trabalhos que apresentavam os requisitos de acordo com a metodologia adotada e que tiveram resultados positivos, no entanto, avaliando os produtos provenientes de plantas em promastigotos. O promastigoto é a forma infecciosa e flagelada do parasita Leishmania. Este que é inoculado no hospedeiro pelo inseto no momento da picada. Comparativamente, pode-se notar que mais trabalhos avaliaram a ação anti-Leishmania em promastigotos do que nos amastigotos.

Assim como nos trabalhos com amastigotos, em muitos casos foram utilizados os óleos essenciais das plantas (ALOUI et al., 2016; ANDRADE et al., 2016; CARVALHO et al., 2017; de MELO et al., 2013; ESSID et al., 2015; MACHADO et al., 2012; MONZOTE et al., 2014; MONZOTE et al., 2014; MUKHERJEE et al., 2016; RODRIGUES et al., 2015; RODRIGUES et al., 2013; VARELA et al., 2016). Apesar de não ser o mesmo tipo celular, os mecanismos de ação propostos foram semelhantes entre as duas formas do parasitas.

Um alvo proposto por alguns autores foi a membrana plasmática do Leishmania (DINESH et al., 2017). O parasito possui uma via metabólica chamada de via mevalonato onde são sintetizados esteróis e isoprenoides. O ergosterol é o componente principal da membrana plasmática deste organismo e está relacionado com a manutenção da integridade estrutural celular e proteção contra estresses bióticos (GALEA \& BROWN, 2009). Assim, é considerado um bom alvo seletivo para fármacos contra a leishmaniose.

O ácido glicirrízico (GA) é o composto ativo da Glycyrrhiza glabra e já foi descrito como tendo atividades antimicrobianas, antivirais, antialérgicas e antioxidantes (DINESH et al., 2017). Além disso, já foram propostos diversos mecanismos de ação para como este ácido é capaz de inibir o crescimento de alguns parasitos, como alteração na imunomodulação do hospedeiro, com aumento de liberação de citocinas em macrófagos infectados por Leishmania (BHATTACHARJEE et al., 2012).

A entrada do parasito no macrófago ocorre com a ligação deste em receptores fagocíticos específicos (LOVE; MENTINK KANE; MOSSER, 1998). Só o fato de Leishmania ser um parasito intracelular, ele consegue evadir a resposta imune via anticorpos do hospedeiro (SACKS; SHER, 2002). Além disso, já foi descrito que $L$. major é capaz de induzir a interleucina 10 (IL-10) (Th2), produzindo células T $\mathrm{CD} 25^{+}$regulatórias evitando a remoção total do parasito (BELKAID et al., 2001). Por outro lado, animais considerados resistentes à infecção por L. major apresentam como característica a produção de IL-12 e IFN- $\gamma$ (Th1), que são citocinas extremamente importantes para a síntese de óxido nítrico no interior da célula infectada, reduzindo assim a carga parasitária (BEAMAN; BEAMAN, 1984; HEINZEL et al., 1989).

Além disso, o parasito apresenta um arsenal de moléculas com a finalidade de burlar o funcionamento adequado do sistema imune do hospedeiro, como por exemplo a LACK (um análogo do receptor da Kinase $\mathrm{C}$ de mamíferos) que parece estar envolvida com a indução de uma resposta tipo Th2 na infecção por L.major (KELLY; STETSON; LOCKSLEY, 2003) as Cisteíno-Peptidases (CP), que são proteínas relacionadas com o processo de diferenciação de promastigotas para amastigotas, assim como na ativação de uma resposta imune tipo Th2 (SILVA-ALMEIDA et al., 2012; WILLIAMS et al., 2006), a Fosfatidilserina (PS), cuja exposição na superfície da membrana de L. amazonensis simula a apoptose de parasito e induz à sua fagocitose de maneira silenciada, favorecendo assim a sobrevivência no interior do vacúolo parasitóforo (EL-HANI, 2012; WANDERLEY; BARCINSKI, 2010). Além disso, quando infectado por um promastigoto, é desencadeado no macrófago do hospedeiro um mecanismo oxigênio-dependente que visa a eliminação do organismo. Neste, são sintetizadas espécies intermediárias reativas de oxigênio, como $\mathrm{H}_{2} \mathrm{O}_{2}$, radical $\mathrm{OH}$ e ânion de superóxido $\left(\mathrm{O}_{2}^{-}\right)$(BEAMAN; BEAMAN, 1984). No entanto, muitos patógenos intracelulares são capazes de detoxificar as espécies reativas de oxigênio, conseguindo persistir e sobreviver no interior do macrófago (GHOSH; GOSWAMI; ADHYA, 2003).

GA foi capaz de suprimir o crescimento in vitro de promastigos e amastigotos de L. donovani, bem abaixo da concentração considerada como citotóxica (DINESH et al., 2017). Dessa forma, concluiu-se que GA é capaz de se ligar a uma enzima específica da biossíntese de ergosterol causando redução em sua produção e consequente morte ao parasita (DINESH et al., 2017).

Assim, é possível que um composto ativo de uma planta tenha mais de um alvo na célula, sendo capaz de interferir de diferentes maneiras dependendo do tipo celular e dos alvos disponíveis (DINESH et al., 2017). Ademais, no caso 
de disparidade na atividade anti-Leishmania de um mesmo fitoterápico, isso pode ser explicado pelas diferenças bioquímicas e metabólicas entre os dois estágios de vida do parasita (GUPTA; GOYAL; RASTOGI, 2001).

Na tabela 3 estão descritos os resultados positivos referentes aos trabalhos que utilizaram algum produto vegetal como tratamento para leishmaniose cuja investigação foi realizada com a forma amastigota do parasito. Nesse momento do ciclo de vida, o parasito já está dentro do macrófago do hospedeiro, se multiplicando (SINGH et al., 2014). Mesmo assim, modelos utilizando este tipo celular de Leishmania são importantes pois são os amastigotos os responsáveis pelas manifestações clínicas da leishmaniose (DI GIORGIO et al., 2005). Além disso, é a melhor maneira de relacionar a atividade in vitro de uma droga anti-Leishmania com sua efetividade (MARTINEZ-ROJANO ET AL., 2008).

Com base nos mecanismos de ação propostos pelos autores dos trabalhos realizados com amastigotos de Leishmania, pode concluir que grande parte está associada com estresse oxidativo na célula e com alterações no ambiente do macrófago, criando espécies reativas que funcionam como microbiocidas (ALAWA et al., 2012; ARRAIS-SILVA et al., 2014; BECERRA et al., 2015; CARRARA et al., 2013; CARVALHO et al., 2017; MUKHERJEE et al., 2016; RODRIGUES et al., 2015; RUDRAPAUL et al., 2014).

Um dos principais mecanismos do hospedeiro para eliminação de patógenos é a produção de óxido nítrico, por meio da enzima óxido nítrico sintetase induzível (OLEKHNOVITCH; BOUSSO, 2015). IFN- $\gamma$ produzido pelas células Th1 induzirão produção da enzima óxido nítrico sintetase induzível nos macrófagos. Essa enzima catalisa a oxidação do nitrogênio guanidino da L-arginina em óxido nítrico, causando a morte do patógeno (HORTA et al., 2012; OLEKHNOVITCH; BOUSSO, 2015).

Já em outros trabalhos (DEZAKI et al., 2016; RODRIGUES et al., 2013; VARELA et al., 2016), o mecanismo de ação do produto vegetal tem como alvo de ação a membrana plasmática, aumentando a sua permeabilidade ou despolarizando-a, e fazendo com que a célula sofra lise.

O mecanismo de ação da folha de Scrophularia striata Boiss contra L. major foi o mais distinto dentre os mecanismos propostos. Zahiri et al. (2016) dizem que a maneira exata como ocorre a inibição ainda não foi estudada em detalhes mas que alcaloides já foram descritos interferindo no metabolismo de aminoácidos aromáticos no parasita (NILFOROUSHZADEH et al., 2008).

Das cerca de 500.000 plantas, estimadas no mundo, grande parte permanece inexplorada com relação ao seu potencial de uso na medicina, produtos naturais e não processados são utilizados pela humanidade há séculos e passados através do conhecimento popular (KHAN et al., 2015). A identificação de produtos naturais e a ampla gama de técnicas de separação disponíveis aumentam a chance de se encontrarem novos produtos efetivos contra infecções por protozoários e podem ser fonte de novos e mais específicos compostos antileishmania (BAPELA; KAISER; MEYER, 2017; RIBEIRO et al., 2014).

Independente da classe de metabólitos (alcaloides, terpenoides, flavonoides e outros polifenois) significante efeito antiprotozoário tem sido observado (SANDJO et al., 2016). Principalmente pelas propriedades antiparasitárias e o modo de ação altamente seletivo (SINGH et al., 2014).

Com base nos resultados aqui explorados pode-se dizer que o uso de fitoterápicos no tratamento da leishmaniose é uma alternativa promissora aos fármacos utilizados atualmente. No entanto, é importante que mais estudos sejam realizados especialmente visando investigar se os compostos ativos das plantas utilizadas possuem efeitos citotóxicos e como estes se comportam in vivo.

\section{Conclusão}

Com base na pesquisa bibliográfica e revisão sistemática realizada, o viés de utilização da produtos vegetais como forma de tratar a leishmaniose existe e é muito viável. As vantagens da utilização da fitoterapia incluem o baixo custo, baixa incidência de efeitos colaterais e sua efetividade. Comparado com as drogas farmacêuticas utilizadas atualmente para tratamento da leishmaniose, que possuem alta toxicidade e que já existem mecanismos pelos quais os parasitos se tornam resistente a estes junto com o fato de não ter uma vacina efetiva contra esta doença, isso representa uma saída possível nos locais onde a incidência da leishmaniose é alta. Além disso, é necessário que sejam consideradas as espécies vegetais disponíveis no local, visando a diminuição nos custos do fitoterápico. Finalmente, é importante que as pesquisas com diferentes fitoterápicos tenham prosseguimento para que possam desenvolver os medicamentos a base de plantas mais seguro e eficaz possível, sempre visando a segurança do paciente.

\section{Referências}

AL-MUSAYEIB, N. M. et al. Study of the in vitro antiplasmodial, antileishmanial and antitrypanosomal activities of medicinal plants from Saudi Arabia. Molecules, v. 17, n. 10, p. 11379-11390, 2012.

AL-SOKARI, S. S. et al. Evaluation of Antileishmanial Activity of Albaha Medicinal Plants against Leishmania amazonensis. BioMed Research International, p. 1-6, 2015.

ALAWA, J. N. et al. Infectivity of Macrophages and the Histopathology of Cutaneous Lesions, Liver and Spleen is Attenuated by Leaf Extract of Vernonia Amygdalina in Leishmania Major Infected BALB/c Mice. Journal of Complementary and Integrative Medicine, v. 9, n. 1, 2012.

ALOUI, Z. et al. Asteraceae Artemisia campestris and Artemisia herba-alba Essential Oils Trigger Apoptosis and Cell Cycle Arrest in Leishmania infantum Promastigotes. Evidence-Based Complementary and Alternative Medicine, v. 1, n. 15, 2016

AMIN, E.; MOAWAD, A.; HASSAN, H. Biologicallyguided isolation of leishmanicidal secondary metabolites from Euphorbia peplus L. Saudi Pharmaceutical Journal, p. 4-8, 2016.

ANDRADE, M. A. et al. Essential oils: in vitro activity against Leishmania amazonensis, cytotoxicity and chemical 
composition. BMC Complementary and Alternative Medicine, v. 16, n. 1, p. 444, 2016.

ANTINARELLI, L. M. R. et al. Antileishmanial activity of some brazilian plants, with particular reference to Casearia sylvestris. Anais Da Academia Brasileira de Ciencias, v.87, n.2, p.733-742, 2015.

ARRAIS-SILVA, W. W. et al. Preliminary phytochemical and antileishmanial studies of the ethanolic extracts of Pterodon pudescens. Revista Brasileira de Plantas Medicinais, v. 16, p. 561-565, 2014.

BAHMANI, M. et al. Leishmaniosis phytotherapy: Review of plants used in Iranian traditional medicine on leishmaniasis. Asian Pacific Journal of Tropical Biomedicine, v. 5, n. 9, p. 695-701, 2015.

BAPELA, M. J.; KAISER, M.; MEYER, J. J. M. South African Journal of Botany Antileishmanial activity of selected South African plant species. South African Journal of Botany, v. 108, p. 342-345, 2017.

BEAMAN, L.; BEAMAN, B. L. The Role of Oxygen and its Derivatives in Microbial Pathogenesis and Host Defense. Annual Review of Microbiology, v. 38, n. 1, p. 27-48, 1984.

BECERRA, M. et al. Antileishmanial activity of fucosterol recovered from Lessonia vadosa Searles (Lessoniaceae) by SFE, PSE and CPC. Phytochemistry Letters, v. 11, p. 418423, 2015.

BEER, M. F. et al. Trypanocidal and leishmanicidal activities of flavonoids isolated from Stevia satureiifolia var. satureiifolia. Pharmaceutical Biology, v. 54, n. 10, p. 1-8, 2016.

BELKAID, Y. et al. The role of interleukin (IL)-10 in the persistence of Leishmania major in the skin after healing and the therapeutic potential of anti-IL-10 receptor antibody for sterile cure. The Journal of Experimental Medicine, v. 194, n. 10, p. 1497-506, 2001.

BHATTACHARJEE, S. et al. Glycyrrhizic acid suppresses Cox-2-mediated anti-inflammatory responses during Leishmania donovani infection. Journal of Antimicrobial Chemotherapy, v. 67, n. 8, p. 1905-1914, 2012.

BOU, D. D. et al. Antiparasitic activity and effect of casearins isolated from Casearia sylvestris on Leishmania and Trypanosoma cruzi plasma membrane. Phytomedicine, v. 21, n. 5, p. 676-681, 2014.

CABANILLAS, B. J. et al. Leishmanicidal compounds and potent PPAR $\gamma$ activators from Renealmia thyrsoidea (Ruiz \& Pav.) Poepp. \& Endl. Journal of Ethnopharmacology, v. 157, p. $149-155,2014$.

CARNEIRO, S. M. P. et al. The cytotoxic and antileishmanial activity of extracts and fractions of leaves and fruits of Azadirachta indica (A Juss.). Biological Research, v. 45, n. 2, p. 111-116, 2012.

CARRARA, V. da S. et al. Antileishmanial activity of amides from Piper amalago and synthetic analogs. Brazilian Journal of Pharmacognosy, v. 23, n. 3, p. 447454, 2013.

CARVALHO, C. E. S. et al. Anti-Leishmania activity of essential oil of Myracrodruon urundeuva (Engl.) Fr. All. Composition, cytotoxity and possible mechanisms of action. Experimental Parasitology, 2017.

DA SILVA SANTOS, E. et al. Optimization of extraction method and evaluation of antileishmanial activity of oil and nanoemulsions of Pterodon pubescens benth. fruit extracts. Experimental Parasitology, v. 170, p. 252-260, 2016.

DA SILVA SANTOS, É. et al. Optimization of extraction method and evaluation of antileishmanial activity of oil and nanoemulsions of Pterodon pubescens benth. fruit extracts. Experimental Parasitology, v. 170, p. 252-260, 2016.

DAL PICOLO, C. R. et al. Antileishmanial activity evaluation of adunchalcone, a new prenylated dihydrochalcone from Piper aduncum L. Fitoterapia, v. 97, p. 28-33, 2014.

DAYAKAR, A. et al. In vitro and in vivo evaluation of antileishmanial and immunomodulatory activity of Neem leaf extract in Leishmania donovani infection. Experimental Parasitology, v. 153, p. 45-54, 2015.

DE ALBUQUERQUE MELO, G. M. et al. Leishmanicidal activity of the crude extract, fractions and major piperidine alkaloids from the flowers of Senna spectabilis. Phytomedicine, v. 21, n. 3, p. 277-281, 2014.

DE MELO, J. O. et al. Antidermatophytic and antileishmanial activities of essential oils from Lippia gracilis Schauer genotypes. Acta Tropica, v. 128, n. 1, p. 110-115, 2013.

DEZAKI, E. S. et al. Chemical composition along with anti-leishmanial and cytotoxic activity of Zataria multiflora. Pharmaceutical Biology, v. 54, n. 5, p. 752-758, 2016.

DI GIORGIO, C. et al. In Vitro Antileishmanial Activity of Diphyllin Isolated from Haplophyllum bucharicum. Planta Medica, v. 71, n. 4, p. 366-369, 2005.

DINESH, N. et al. Glycyrrhizic acid attenuates growth of Leishmania donovani by depleting ergosterol levels. Experimental Parasitology, v. 176, p. 21-29, 2017.

DUARTE, M. C. et al. Antileishmanial activity and mechanism of action from a purified fraction of Zingiber officinalis Roscoe against Leishmania amazonensis. Experimental Parasitology, v. 166, p. 21-28, 2016.

EL-HANI, C. Apoptosis and apoptotic mimicry in 
Leishmania: an evolutionary perspective. Frontiers in Cellular and Infection Microbiology, v. 2, 96.

ESSID, R. et al. Antileishmanial and cytotoxic potential of essential oils from medicinal plants in Northern Tunisia.

Industrial Crops and Products, v. 77, p. 795-802, 2015.

FALODUN, A. et al. Isolation of antileishmanial, antimalarial and antimicrobial metabolites from Jatropha multifida. Asian Pacific Journal of Tropical Biomedicine, v. 4 , n. 5, 374-8, 2014.

FILHO, V. C. et al. Evaluation of antileishmanial activity of selected brazilian plants and identification of the active principles. Evidence-Based Complementary and Alternative Medicine, v. 1, n. 7, 2013.

GALEA, A. M.; BROWN, A. J. Special relationship between sterols and oxygen: Were sterols an adaptation to aerobic life? Free Radical Biology and Medicine, v. 47, n. 6, p. 880-889, 2009.

GANFON, H. et al. Antiparasitic activities of two sesquiterpenic lactones isolated from Acanthospermum hispidum D.C. Journal of Ethnopharmacology, v. 141, n. 1, p. 411-417, 2012.

GHOSH, S.; GOSWAMI, S.; ADHYA, S. Role of superoxide dismutase in survival of Leishmania within the macrophage. Biochemical Journal, v. 369, n. 3, p. 447-452, 2003.

GIRARDI, C. et al. Evaluation of antiplasmodial and antileishmanial activities of herbal medicine Pseudelephantopus spiralis (Less.) Cronquist and isolated hirsutinolide-type sesquiterpenoids. Journal of Ethnopharmacology, v. 170, p. 167-174, 2015.

GUPTA, N.; GOYAL, N.; RASTOGI, A. K. In vitro cultivation and characterization of axenic amastigotes of Leishmania. Trends in Parasitology, v. 17, n. 3, p.150-153, 2001 .

HEINZEL, F. P. et al. Reciprocal expression of interferon gamma or interleukin 4 during the resolution or progression of murine leishmaniasis. Evidence for expansion of distinct helper T cell subsets. The Journal of Experimental Medicine, v. 169, n. 1, p. 59-72, 1989.

HORTA, M. F. et al. Reactive Oxygen Species and Nitric Oxide in Cutaneous Leishmaniasis. Journal of Parasitology Research, v. 2012, p. 1-11, 2012

HUBERT, D. J. et al. In vitro leishmanicidal activity of some Cameroonian medicinal plants. Experimental Parasitology, v. 134, n. 3, p. 304-308, 2013.

KAYE, P.; SCOTT, P. Leishmaniasis: complexity at the host-pathogen interface. Nature Reviews. Microbiology, v. 9 , n. 8, p. 604-615, 2011.
KELLY, B. L.; STETSON, D. B.; LOCKSLEY, R. M. Leishmania major LACK antigen is required for efficient vertebrate parasitization. The Journal of Experimental Medicine, v. 198, n. 11, p. 1689-98. 2003.

KHAN, I. et al. Evaluation of antileishmanial, antibacterial and brine shrimp cytotoxic potential of crude methanolic extract of Herb Ocimum basilicum (Lamiacea). Journal of Traditional Chinese Medicine, v. 35, n. 3, p. 316-322, 2015.

KHEIRI MANJILI, H. et al. Anti-leishmanial and toxicity activities of some selected Iranian medicinal plants. Parasitology Research, v. 111, n. 5, p. 2115-2121, 2012.

LIMA, G. S. et al. Antileishmanial activity and trypanothione reductase effects of terpenes from the Amazonian species Croton cajucara Benth (Euphorbiaceae). Phytomedicine, v. 22, n. 12, p. 1133-1137, 2015.

LOVE, D. C.; MENTINK KANE, M.; MOSSER, D. M. Leishmania amazonensis: the phagocytosis of amastigotes by macrophages. Experimental Parasitology, v. 88, n. 3, p. 161-71, 1998.

MACHADO, M. et al. Monoterpenic aldehydes as potential anti-Leishmania agents: Activity of Cymbopogon citratus and citral on L. infantum, L. tropica and L. major. Experimental Parasitology, v. 130, n. 3, p. 223-231, 2012.

MALEKI, F. et al. In vitro and in vivo susceptibility of Leishmania major to some medicinal plants. Asian Pacific Journal of Tropical Biomedicine, v. 7, n. 1, p. 37-42, 2016.

MANS, D. R. A. et al. In vitro evaluation of traditionally used Surinamese medicinal plants for their potential antileishmanial efficacy. Journal of Ethnopharmacology, v. 180, p. 70-77, 2016.

MAQUIAVELI, C. do C. et al. Stachytarpheta cayennensis extract inhibits promastigote and amastigote growth in Leishmania amazonensis via parasite arginase inhibition. Journal of Ethnopharmacology, v. 192, p. 108-113, 2016.

MARTINEZ-ROJANO, H. et al. Activity of Hydroxyurea against Leishmania mexicana. Antimicrobial Agents and Chemotherapy, v. 52, n. 10, p. 3642-3647, 2008.

MCCONVILLE, M. J.; HANDMAN, E. The molecular basis of Leishmania pathogenesis. International Journal for Parasitology, v. 37, n. 10, p. 1047-1051, 2007.

MOEIN, M. et al. Antileishmanial Activities of Greek Juniper ( Juniperus excelsa M.Bieb.) Against Leishmania major Promastigotes. Journal of Evidence-Based Complementary \& Alternative Medicine, v. 22, n. 1, p. 31-36, 2017.

MONZOTE, L. et al. Essential oil from Chenopodium ambrosioides and main components: Activity against 
Leishmania, their mitochondria and other microorganisms. Experimental Parasitology, v. 136, n. 1, p. 20-26, 2014.

MONZOTE, L. et al. Antileishmanial activity of essential oil from Chenopodium ambrosioides and its main components against experimental cutaneous leishmaniasis in BALB/c mice. Phytomedicine, v. 21, p. 8-9, 2014.

MOTHANA, R. A. et al. Evaluation of the in vitro antiplasmodial, antileishmanial and antitrypanosomal activities of selected medicinal plants from the Arabian Peninsula. Planta Med, v. 79, n. 13, p. 24, 2013.

MUKHERJEE, D. et al. Induction of apoptosis by zerumbone isolated from Zingiber zerumbet (L.) Smith in protozoan parasite Leishmania donovani due to oxidative stress. Brazilian Journal of Infectious Diseases, v. 20, n. 1, p.48-55, 2016.

NIKMEHR, B. et al. In vitro anti-leishmanial activity of methanolic extracts of Calendula officinalis flowers, Datura stramonium seeds, and Salvia officinalis leaves. Chinese Journal of Natural Medicines, v. 12, n. 6, p. 423-427, 2014.

NILFOROUSHZADEH, M. A. et al. Comparison of Thymus vulgaris (Thyme), Achillea millefolium (Yarrow) and propolis hydroalcoholic extracts versus systemic glucantime in the treatment of cutaneous leishmaniasis in balb/c mice. Journal of Vector Borne Diseases, v. 45, n. 4, p. 301-6, 2008.

OLEKHNOVITCH, R.; BOUSSO, P. Induction, Propagation, and Activity of Host Nitric Oxide: Lessons from Leishmania Infection. Trends in Parasitology, v.31, n.12, p.653-664, 2015.

OSKUEE, R. K. et al. Evaluation of leishmanicidal effect of Euphorbia erythadenia extract by in vitro leshmanicidal assay using promastigotes of Leishmania major. Asian Pacific Journal of Tropical Biomedicine, v. 4, s. 2, p. 581583, 2014.

RIBEIRO, T. G. et al. Antileishmanial activity and cytotoxicity of Brazilian plants. Experimental Parasitology, v. 143, n. 1, p. 60-68, 2014.

RODRIGUES, K. A. D. F. et al. Syzygium cumini (L.) Skeels essential oil and its major constituent $\alpha$-pinene exhibit anti-Leishmania activity through immunomodulation in vitro. Journal of Ethnopharmacology, v. 160, p. 32-40, 2015.

RODRIGUES, K. A. DA F. et al. Eugenia uniflora L. Essential Oil as a Potential Anti- Leishmania Agent: Effects on Leishmania amazonensis and Possible Mechanisms of Action. Evidence-Based Complementary and Alternative Medicine, v. 2013, n. 1, 2013.

ROSSI, D. et al. (R)-(-)-Aloesaponol III 8-methyl ether from eremurus persicus: A novel compound against leishmaniosis. Molecules, v. 22, n. 4, 2017.

RUDRAPAUL, P. et al. New flavonol methyl ether from the leaves of Vitex peduncularis exhibits potential inhibitory activity against Leishmania donovani through activation of iNOS expression. European Journal of Medicinal Chemistry, v. 87, p. 328-335, 2014.

SACHDEVA, H.; SEHGAL, R.; KAUR, S. Tinospora cordifolia as a protective and immunomodulatory agent in combination with cisplatin against murine visceral leishmaniasis. Experimental Parasitology, v. 137, n. 1, p. 53-65, 2014.

SACKS, D.; SHER, A. Evasion of innate immunity by parasitic protozoa. Nature Immunology, v. 3, n. 11, 2002.

SANDJO, L. P. et al. Individual and combined antiparasitic effect of six plant metabolites against Leishmania amazonensis and Trypanosoma cruzi. Bioorganic and Medicinal Chemistry Letters, v. 26, n. 7, p. 1772-1775, 2016.

SANTOS, K. K. A. et al. Atividade leishmanicida in vitro de Eugenia uniflore Momordica charantia. Rev Ciênc Farm Básica Apl., v. 34, n. 1, p. 47-50, 2013.

SAWADOGO, W. R. et al. In vitro antileishmanial and antitrypanosomal activities of five medicinal plants from Burkina Faso. Parasitology Research, v. 110, n. 5, p. 17791783, 2012.

SILVA-ALMEIDA, M. et al. Proteinases as virulence factors in Leishmania spp. infection in mammals. Parasites \& Vectors, v. 5, n. 1, p. 160, 2012.

SINGH, N. et al. Natural product based leads to fight against leishmaniasis. Bioorganic and Medicinal Chemistry, v. 22, n. 1, p. 18-45, 2014.

TRIPATHI, C. D. P. et al. Withania somnifera chemotype NMITLI 101R significantly increases the efficacy of antileishmanial drugs by generating strong IFN- $\gamma$ and IL12 mediated immune responses in Leishmania donovani infected hamsters. Phytomedicine, v. 24, 2017.

VANDESMET, V. C. S. et al. The use of herbs against neglected diseases: Evaluation of in vitro leishmanicidal and trypanocidal activity of Stryphnodendron rotundifolium Mart. Saudi Journal of Biological Sciences. 2015.

VARELA, M. T. et al. Gibbilimbol analogues as antiparasitic agents - Synthesis and biological activity against Trypanosoma cruzi and Leishmania (L.) infantum.

Bioorganic and Medicinal Chemistry Letters, v. 26, n. 4, 2016.

VILA-NOVA, N. S. et al. Different susceptibilities of Leishmania spp. promastigotes to the Annona muricata acetogenins annonacinone and corossolone, and the Platymiscium floribundum coumarin scoparone. 
Experimental Parasitology, v. 133, n. 3, p. 334-338, 2013.

VILA-NOVA, N. S. et al. Leishmanicidal and cholinesterase inhibiting activities of phenolic compounds of Dimorphandra gardneriana and Platymiscium floribundum, native plants from Caatinga biome. Pesquisa Veterinaria Brasileira, v. 32, n. 11, p. 1164-1168, 2012.

WANDERLEY, J. L. M.; BARCINSKI, M. A. Apoptosis and apoptotic mimicry: The Leishmania connection. Cellular and Molecular Life Sciences, 2010.

WILLIAMS, R. A. et al. Cysteine peptidases CPA and CPB are vital for autophagy and differentiation in Leishmania mexicana. Molecular Microbiology, v. 61, n. 3, p. 655-674, 2006.

ZAHIR, A. A. et al. Evaluation of antileishmanial activity of South Indian medicinal plants against Leishmania donovani. Experimental Parasitology, v. 132, n. 2, p. 180-184, 2012.

ZAHIRI, M. et al. Therapeutic Effect of Scrophularia striata Ethanolic Extract against Localized Cutaneous Leishmaniasis Caused by Leishmania major (MRHO/IR/75/ ER). Iranian Journal of Public Health, v. 45, n. 10, 2016.

Recebido: 29/10/2017 Aceito: $04 / 08 / 2018$ 